Chapter 30

HURRICANE TIDE PREDICTION FOR NEW YORK BAY

\author{
Basil W. Wilson \\ Professor, Department of Oceanography and Meteorology \\ Texas A. \& M. College, College Station, Texas
}

\begin{abstract}
This paper is concerned with the solution of the problem of correlating, on a two-dimensional basis, the meteorological parameters of several off-shore storms with the known surge induced by them in New York Bay and with the application of the results to the prediction of likely effects in New York Bay from a design hurricane of given strength traversing a given path at a given speed. A purely theoretical approach would have been beyond practical possibility within the time available for this study; the method adopted therefore is empirical but with some degree of theoretical guidance. A recursion formula is evolved, using the method of finite differences for time increments of $1 / 3$ hour, which relates tide elevation at the bay-mouth with two values of the elevation at $1 / 3$ and $2 / 3$ hour earlier and with values of wind-stress and pressure-gradient driving-force components (directed towards New York Bay from several remote two-dimensionally spaced offshore-stations on the continental shelf) at times earlier by the periods taken for free long gravity waves to travel from the stations to the bay-mouth. The formula includes a comulative forcing function term which allows for the geostrophic influence of the earth's rotation and also for an "edge-wave" effect northward along the eastern seaboard. Moreover it takes into account the observed tendencies of hurricane storm tides in New York Bay to develop resurgences at periods of 7 hours with decay rates of $50 \%$ amplitude decrease per cycle. The coefficients of the "forcing functions", determined by correlation, tend to represent the storm size and speed and also the dynamic augmentation of the forced wave. Predicted maximum storm tide heights are in fair agreement with crude empirical estimates based on central pressures within the hurricanes. Predictions, however, provide complete time-sequences of water level for periods up to 24 hours inclusive of the first resurgence after the main surge.
\end{abstract}




\section{HURRICANE TIDE PREDICTION FOR NEW YORK BAY}

\section{INTRODUCTION}

The two-dimensional problem of a non-radially symmetric tropical storm approaching an irregular coastline over water of shelving depth at variable speed is, theoretically, of formidable proportions and, so far as is known, has not yet been solved. The best hope for its eventual solution in special cases lies in the use of finite-difference procedures. Some notable advances have been made in this direction by such investigators as Hansen, Weylander, Kreiss [Reid 1957 (i)], Kivisild [1954], Reid [1957 (ii)], Platzman [1958], Fischer [1959] and others, and these lend hope that the difficulties of the problem may finally be overcome. The major difficulties concern the boundary conditions at the edge of the continental shelf, seaward of which the response of the sea surface to the storm driving forces may be quite unknown; here also the reflective properties of the continental slope may be difficult to determine.

To avoid these inherent problems and withal reach reasonable estimates (within a short time) of the potential menace of hurricane storm tides to New York Bay it was decided to use an empirical approach under the guidance of theory. The method here described differs rather considerably from other empirical methods devised for the North Sea area by Schalkwijk [1947], Corkan [1950], the Darbyshires [1956], Hansen [1957], Weenink and Groen [1958], and others. It departs also from the several empirical endeavours of American investigators who have previously studied surge effects along the United States east coast, notably Miller [1956], Zetler [1957], Kussman [1957], Donn [1958] and Tancreto [1958] as also Reid [1955], Conner, et al [1957], Hoover [1957], Dunn [1957], and Harris [ 1957,1959$]$. Most of these empirical approaches are unsuited to transient, fast-moving circular storms in which inertial effects and influences of the earth's rotation are likely to be important.

In what follows an attempt is made to take due account of the speed of the storm, the direction of its approach, the two-dimensional topography of the continental shelf area which it would have to traverse, the size of the storm, its meteorological parameters (pressure and wind velocity) in a two dimensional sense, its geostrophic effect along-shore and its dynamic effect in producing inertial oscillations of the observed period, magnitude and evanescence. 


\section{TWO-DIMENSIONAL MOTION OF WATER UNDER IMPULSION FROM ATMOSPHERIC DRIVING FORCES}

With reference to a rectangular co-ordinate system having its origin and $x y$-plane in the horizontal still water surface, the equations of motion and continuity of the water at any point $(x, y)$ may be rendered in the form,

for motion in the $x$-direction,

$$
\frac{\partial Q_{x}}{\partial t}-f Q_{y}+g(d+\eta) \frac{\partial \eta}{\partial x}=\frac{\tau_{s x}-\tau_{b x}}{\rho}-\frac{(d+\eta)}{\rho} \frac{\partial p_{a}}{\partial x}
$$

for motion in the $\mathrm{y}$ direction,

$$
\frac{\partial Q_{y}}{\partial t}+f Q_{x}+g(d+\eta) \frac{\partial \eta}{\partial y}=\frac{\tau_{s y}-\tau_{b y}}{p}-\frac{(d+\eta)}{p} \frac{\partial p_{a}}{\partial y}
$$

for continuity,

$$
\frac{\partial Q_{x}}{\partial x}+\frac{\partial Q_{y}}{\partial y}+\frac{\partial \eta}{\partial t}=0
$$

In these equations $Q_{x}, Q_{y}$ are the volumes of water transported in unit time in the $x, y$ directions respectively across vertical sections of unit width between the free surface and the bottom, $\eta$ is the elevation of the water surface above the still water level, $d$ the nominal water depth ( referred to still water), f the coriolis parameter, $\tau_{\mathrm{sx}}, \tau_{\mathrm{sy}}$ the $\mathrm{x}, \mathrm{y}$ components of the surface wind stress, $\tau_{b x}, \tau_{b y}$ the corresponding components of the bottom frictional stress, $\mathrm{p}_{\mathrm{a}}$ the atmospheric pressure, and $g, p, t$ the usual respective designations for acceleration due to gravity, mass density of water, and variable time.

The assumptions underlying the above equations are that vertical accelerations of the water body resulting from the wind stress $\tau$ and the atmospheric pressure $\mathrm{p}_{a}$ are quite negligible, as are any changes in shear stress within the fluid in horizontal directions; further that the horizontal flow of water is uniform with depth and changes only very gradually with distance, while water density is constant.

It is convenient to approximate $\frac{1}{0} \tau_{\mathrm{bx}}, \frac{1}{0} \tau_{\mathrm{by}}$ as proportional to $\mathrm{Qx}_{\mathrm{x}}, \mathrm{Q}_{\mathrm{y}}$ respectively by use of a friktional damping constant $\mathrm{K}$ so that, on regarding $\eta$ as small in comparison with $d$, Eqs. (1) modify to 
(i)

$$
\left(\frac{\partial}{\partial t}+K\right) Q_{x}-f Q_{y}+g d \frac{\partial \eta}{\partial x}=F_{x}
$$

$$
\left(\frac{\partial}{\partial t}+K\right) Q_{y}+f Q_{x}+g d \frac{\partial \eta}{\partial y}=F_{y}
$$

$$
\frac{\partial Q_{x}}{\partial x}+\frac{\partial Q_{y}}{\partial y}+\frac{\partial \eta}{\partial t}=0
$$

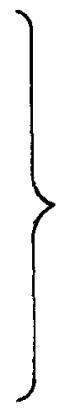

wherein $F_{x}$ and $F_{y}$ are forcing functions representing the wind stress and pressure gradient, as defined by

$$
\begin{aligned}
& \text { (i) } F_{x}=\frac{1}{\rho}\left(\tau_{x}-d \frac{\partial p_{a}}{\partial x}\right) \\
& \text { (ii) } F_{y}=\frac{1}{\rho}\left(\tau_{y}-d \frac{\partial p_{a}}{\partial x}\right)
\end{aligned}
$$

\section{ONE-DIMENSIONAL MOTION IN ABSENCE OF EARTH'S ROTATIONAL INFLUENCE - INFLUENCE OF WIND STRESS}

In order to justify our physical reasoning in what follows, we shall temporarily depart from the two-dimensionality of the problem to consider the one-dimensional $(x)$ problem on the assumption that lateral flow, $Q_{y}$, is non-existent. In these circumstances, Eqs. $(2, i)$ and $(2, i i i)$ reduce to

$$
\begin{gathered}
\frac{\partial Q}{\partial t}+K Q+g d \frac{\partial \eta}{\partial x}=F \\
\frac{\partial Q}{\partial x}+\frac{\partial \eta}{\partial t}=0
\end{gathered}
$$

For convenience the $\mathrm{x}$ subscript is discarded in Eqs. (4). We shall make the further approximation that $\eta$ can be divided into the separate effects, $\eta_{\mathrm{w}}$ and $\eta_{\mathrm{p}}$ deriving from wind stress and pressure gradient respectively, with corresponding flows $\mathrm{Q}_{\mathrm{w}}$ and $\mathrm{Q}_{\mathrm{p}}$, and driving forces $F_{\mathrm{w}}\left(=\frac{{ }^{\top} \mathrm{x}}{\rho}\right)$ and $\mathrm{F}_{\mathrm{p}}\left(=-\frac{\mathrm{d}}{\rho} \frac{\partial \mathrm{p}_{\mathrm{a}}}{\partial \mathrm{x}}\right)$.

Considering first of all the wind effect, it is possible to represent the magnitude of the wind stress, assumed to have an equilateral-triangular distribution (as for a hurricane) [cf Reid, 1955; 1956(i)] over a storm 


\section{COASTAL ENGINEERING}

fetch $2 \ell$ and to be moving forward without change at constant velocity $\mathrm{V}$ across a distance $2 \mathrm{~L}$ from the coast, Fig. 1 (where $\mathrm{L}$ may be assumed to be the shelf width $)^{*}$, as the Fourier series:

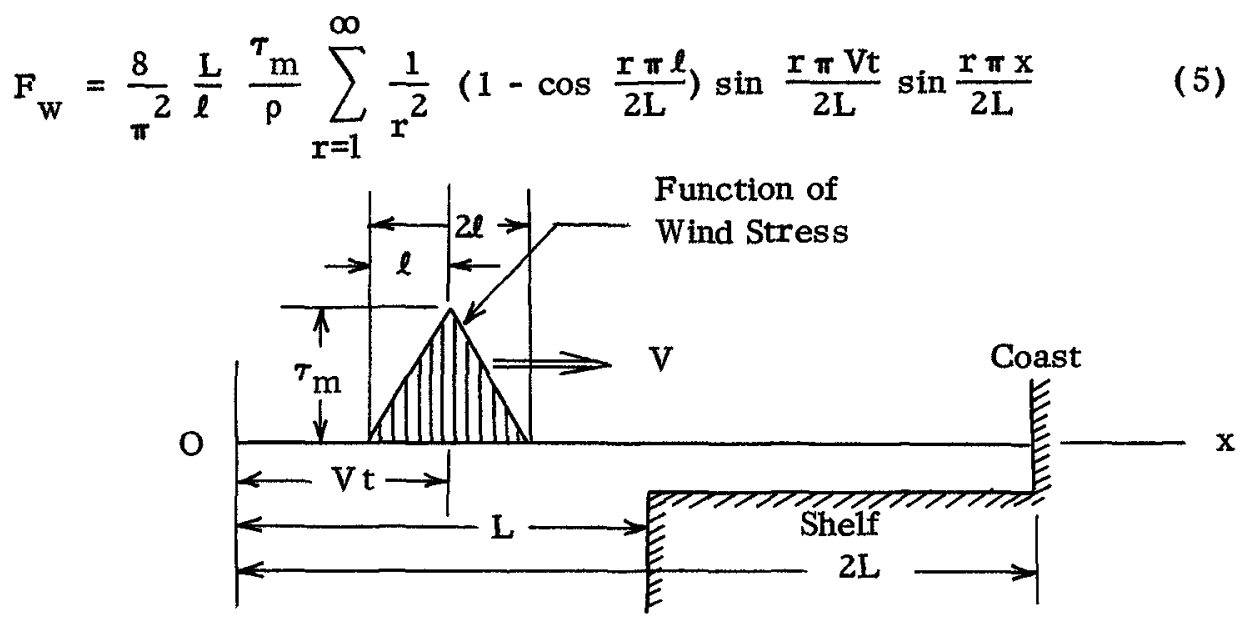

Fig. 1. Representation of Moving Wind Stress Function as a Fourier Series

wherein $\tau_{\mathrm{m}}$ is the maximum value of the wind stress and $\mathbf{r}$ an integer of successive values $1,2,3 \ldots$ It should be remarked here that constancy of $\tau_{\mathrm{m}}$ and $\ell$ with time and distance will really only obtain if the storm is moving parallel to the direction $x$. The representation of Eq. (5) is therefore rather artificial, but will serve the purpose of demonstration.

It is convenient to consider just a general $r$-th term of the Fourier summation, namely, $\left(F_{W}\right)_{r}$ and proceed to a solution of Eq. (4) by trial of possible solutions

$$
\left.\begin{array}{l}
\left(\eta_{w}\right)_{r}=M_{r}(t) \cos \frac{r \pi x}{2 L} \\
\left(Q_{w}\right)_{r}=N_{r}(t) \sin \frac{r \pi x}{2 L}
\end{array}\right\}
$$

* The adoption of $2 \mathrm{~L}$ for the series expansion is merely a convenient artifice to ensure that the moving fetch may initially be seaward of the shelf edge if $\ell<L$. 
in which $M_{r}(t)$ and $N_{r}(t)$ are unknown functions of $t$ which remain to be determined and $\left(\eta_{W} \xi_{r}\right.$ and $\left(Q_{w}\right)_{r}$ are $r$ th terms in the complete solutions

$$
\begin{aligned}
& \eta_{\mathrm{w}}=\sum_{r=1}^{\infty}\left(\eta_{\mathrm{w}}\right)_{\mathrm{r}} \\
& \mathrm{Q}_{\mathrm{w}}=\sum_{r=1}^{\infty}\left(\mathrm{Q}_{\mathrm{w}}\right)_{\mathrm{r}}
\end{aligned}
$$

Upon inserting Eqs. (6) in Eqs. (4), and solving the simultaneous differential equations for $M_{r}(t)$, there results

$$
M_{r}^{\prime \prime}+K M_{r}^{\prime}+\left(\frac{r^{2} \pi^{2}}{4 L^{2}} C^{2}\right) M_{r}=B \sin \left(\frac{r \pi V}{2 L}\right) t
$$

wherein primes denote the order of differentiation of the function $M_{r}(t)$ with respect to $t$ and

$$
\left.\begin{array}{l}
\mathrm{C}^{2}=\mathrm{gd} \\
\mathrm{B}=\frac{4}{\pi} \frac{\tau_{\mathrm{m}}}{\mathrm{\rho} \ell} \frac{1}{\mathrm{r}}\left(1-\cos \frac{\mathrm{r} \pi \ell}{2 \mathrm{~L}}\right)
\end{array}\right\}
$$

\section{SOLUTION OF THE FREE OSCILLATIONS - WIND STRESS EFFECT}

Eq. (8) is the familiar expression for a linear damped oscillating system excited by a disturbance of periodic character. To simplify notation we rewrite it in the form

$$
\frac{d^{2} y}{d t^{2}}+K \frac{d y}{d t}+s_{r}^{2} y=B \sin \omega_{r} t
$$

in which $\mathrm{S}_{\mathrm{r}}$ is an angular frequency very closely that of the free oscillation and $\omega_{r}$ the frequency of the forced oscillation in the $r$-th mode.

We shall concern ourselves here for the time being only with the free, inertial oscillations, represented by the solution of

$$
\frac{d^{2} y}{d t^{2}}+K \frac{d y}{d t}+s_{r}^{2} y=0
$$


By writing Eq. (11) in finite difference form with a small time increment $\tau$, we obtain

$$
\frac{y_{n}-2 y_{n-1}+y_{n-2}}{\tau^{2}}+k \frac{y_{n}-y_{n-1}}{\tau}+s_{x}^{2} y_{n-1}=0
$$

wherein $y_{n}, y_{n-1}, y_{n-2}$ are consecutive values of $y$ at receding small intervals of time $\tau$ with $\mathrm{y}_{\mathrm{n}}$ applicable to any time, $\mathrm{n} \tau$. On solving Eq. (12) for $y_{\mathfrak{n}}$,

$$
y_{n}=a y_{n-1}-b y_{n-2}
$$

in which the coefficients $a, b$ have the values:

$$
\left.\begin{array}{c}
a=\frac{2+K_{\tau}-\left(S_{r} \tau\right)^{2}}{1+K \tau} \\
b=\frac{1}{1+K \tau}
\end{array}\right\}
$$

Returning now to Eq. $(6, i)$ and taking $r=1$ as representing the fundamental mode of possible free oscillations, it would appear that the relationship

$$
\eta_{w}(t)=a \eta_{w}(t-\tau)-b \eta_{w}(t-2 \tau)
$$

would be descriptive of the free oscillations in the fundamental mode. Since the frequency $S(=2 \pi / T, T$ being the period of free oscillation $)$ and the damping coefficient $\mathrm{K}$ are measurable in the records of storm tides, the coefficients $a, b$ are prescribed by Eqs. (14). It may be shown that the values of these coefficients must observe the conditions

$$
4 b>(a)^{2}
$$$$
\mathrm{b}<1
$$

if numerical stability of Eq. (20) is to be ensured.

\section{SOLUTION OF THE FORCED OSCILLA TIONS - WIND STRESS EFFECT}

Determination of the forced oscillations created by the moving wind disturbance involves finding the Particular Integral of Eq. (8) or (10). This 


\section{HURRICANE TIDE PREDICTION FOR NEW YORK BAY}

is readily shown to be

$$
y=\alpha \sin \omega_{r} t+\beta \cos \omega_{r} t
$$

where

$$
\left.\begin{array}{l}
\alpha=\frac{B\left(S_{r}^{2}-\omega_{r}^{2}\right)}{\left(S_{r}^{2}-\omega_{r}^{2}\right)^{2}+\left(K \omega_{r}\right)^{2}} \\
\beta=\frac{-B\left(K \omega_{r}\right)}{\left(S_{r}^{2}-\omega_{r}^{2}\right)^{2}+\left(K \omega_{r}\right)^{2}}
\end{array}\right\}
$$

Discarding the modal subscript $r$ for convenience, we now require that this forced part of the solution [Eq. (17)] should comply with a finite difference solution of the form of Eq. (13), but inclusive of a term directly representative of the forcing function of Eq. (10); that is

$$
y_{n}=a y_{n-1}-b y_{n-2}+c \sin [(n-1) \omega \tau-\gamma] \text {. }
$$

in which $\gamma$ is an appropriate phase angle.

Theoretically it can be shown that the coefficient $\mathrm{c}$ is a function of $B, S, K, \omega \tau$, and $\mu$ of which $\mu$ is a dynamic augmentation factor dependent on the forced-free frequency ratio $(\omega / S)$, namely

$$
\mu=\left[\left\{1-(\omega / S)^{2}\right\}^{2}+\left(K \omega / S^{2}\right)^{2}\right]^{-\frac{1}{2}}
$$

The ratio of frequencies $\omega / \mathrm{S}$ will be apparent on comparison of Eqs. (8) and (10). Thus

$$
\omega / \mathrm{S}=\mathrm{V} / \mathrm{C}
$$

making

$$
\mu=\left[\left\{1-(V / C)^{2}\right\}^{2}+\left(\frac{K}{S} V / C\right)^{2}\right]^{-\frac{1}{2}}
$$

If thus transpires that the finite difference solution

$$
\eta_{w}(t)=a \eta_{w}(t-\tau)-b \eta_{w}(t-2 \tau)+c F_{w}\left[(t-\tau)-T_{0}\right]
$$


wherein $T_{0}$ is a time lag comparable to the phase angle $\gamma$, will represent the dynamic storm tide generated under the impulsion of the wind stress. If the coefficients $a$ and $b$ are prescribed by Eqs. (14) and the coefficient $c$ and the phase $T$ are determined by correlation between $\left[\eta_{w}(t)-a \eta_{w}(t-\tau)+b \eta_{w}(t-2 \tau)\right]$ and $F_{w}(t-\tau)$, then the above dis cussion shows that the formula (24) will inherently allow for any dynamic augmentation arising from the relative magnitudes of the speed of the storm and the velocity of the induced free wave. Further, since the coefficient $c$ is inclusive of the amplitude $B$ of the forcing function [ see Eqs. (8), (9) and $(10)$ ], which tends to depend on the size of the storm (through its fetch $2 \ell$ ), it follows also that the scale of the storm is inherently allowed for in the formula of Eq. (24).

\section{INFLUENCE OF THE PRESSURE GRADIENT}

Considering next the influence of the driving force from pressure gradient, $F_{p}\left(=-\frac{d \partial p_{a}}{p}\right)$, in a hurricane; we may, for purposes of demonstration again, assume the pressure gradient distribution over a moving fetch $2 l$ to be unchanging and of the form $-\frac{\mathrm{d}}{\mathrm{p}}\left(\frac{\partial \mathrm{pa}}{\partial \mathrm{x}}\right) \max$. $X$ $\sin \frac{\pi(x-V t)}{\ell}$ (Fig. 2). Adopting the additional simplification of uniform depth over the distance $2 \mathrm{~L}$, the Fourier series representation of the forcing function may be shown to be

$$
F_{p}=-\frac{8}{\pi} \frac{(\ell L d)}{\rho}\left(\frac{\partial p_{a}}{\partial x}\right) \max \sum_{r=1}^{\infty} \frac{1}{4 L^{2}-(r \ell)^{2}} \sin \frac{r \pi \ell}{2 L} \cos \frac{r \pi V t}{2 L} \sin \frac{r \pi x}{2 L}
$$

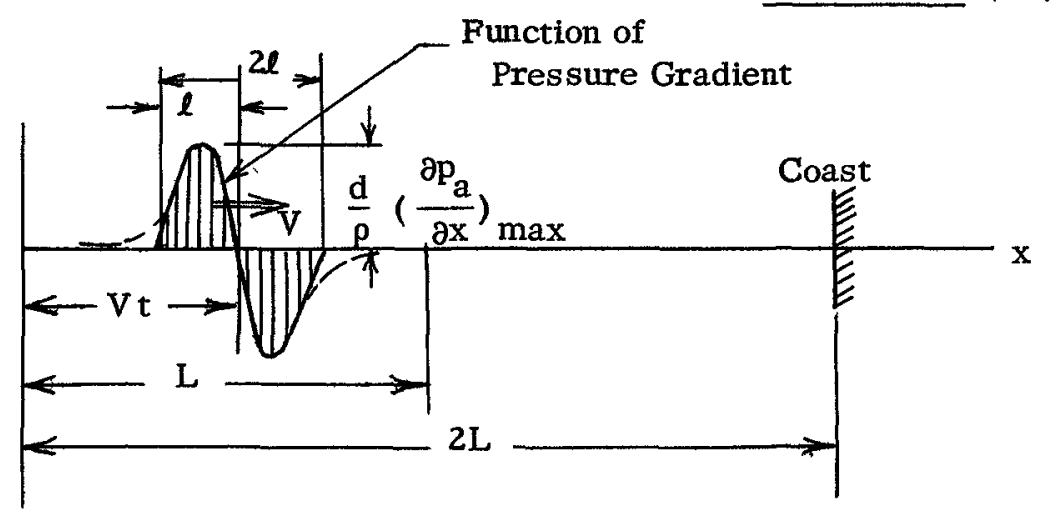

Fig 2. Representation of Moving Pressure Gradient Function as a Fourier Series 


\section{HURRICANE TIDE PREDICTION FOR NEW YORK BAY}

wherein $\left(\frac{\partial \mathrm{p}_{\mathrm{a}}}{\partial \mathrm{x}}\right)_{\max }$ is the maximum value of the pressure gradient and $r$ is again an integer of successive values $r=1,2,3 \ldots \ldots$

Again we consider just a general $r$-th term of the Fourier summation, namely $\left(F_{p}\right)_{r}$, and try as solutions of Eq. (4)

$$
\begin{aligned}
& \left(\eta_{p}\right)_{r}=G_{r}(t) \cos \frac{r \pi x}{2 L} \\
& \left(Q_{p}\right)_{r}=H_{r}(t) \sin \frac{r \pi x}{2 L}
\end{aligned}
$$

in which $G_{r}(t)$ and $H_{r}(t)$ are unknown functions of $t$, to be determined.

Substitution of Eqs. (26) in Eqs. (4) results in

$$
G_{r}^{\prime \prime}+K G_{r}^{\prime}+\left(\frac{r^{2} \pi^{2} C^{2}}{4 L^{2}}\right) G_{r}=D \cos \left(\frac{r \pi V}{2 L}\right) t
$$

wherein primes denote the order of differentiation of the function $G_{r}(t)$ with respect to $t$ and

$$
\left.\begin{array}{c}
\mathrm{C}^{2}=\mathrm{gd} \\
\mathrm{D}=-\frac{4 \mathrm{~d}}{\rho}\left(\frac{\partial \mathrm{p}}{\partial \mathrm{x}}\right)_{\max } \frac{r \ell}{4 \mathrm{~L}^{2}-(\mathrm{r} \ell)^{2}} \sin \frac{r \pi \ell}{2 \mathrm{~L}}
\end{array}\right\}
$$

It is possible to follow the same arguments of the preceding two sections, by writing Eq. (27) in the form

$$
\frac{d^{2} y}{d t^{2}}+K \frac{d y}{d t}+s_{r}^{2} y=D \cos \omega_{r} t
$$

and reach the more general conclusion that a finite difference solution of the form

$\eta(t)=a \eta(t-\tau)-b \eta(t-2 \tau)+c\left[F_{w}\left\{(t-\tau)-T_{o}\right\}+F_{p}\left\{(t-\tau)-T_{o}\right\}\right]$

will represent the combined dynamic storm tide generated by both the wind 


\section{COASTAL ENGINEERING}

stress and pressure gradient driving forces acting together. The last term may conveniently be designated simply as $\mathrm{cF}\left(\mathrm{t}-\tau-\mathrm{T}_{\mathrm{o}}\right)$

\section{ALLOWANCE FOR TWO-DIMENSIONAL EFFECTS}

We return now to the two-dimensional nature of the problem with special reference to the offshore environment in the neighborhood of New York. If a number (N) of offshore stations is arbitrarily selected, as in Fig. 3 (inset), to cover, in a two-dimensional sense, the shelf region of the approaches to New York Bay, then, by evaluating the magnitude of the forcing function $F_{r}\left(t-\tau-T_{N}\right)$ at any such station, directed radially towards the station $A$ at the bay-mouth, (in which $T_{N}$ is the time taken for the free wave to travel from the $\mathrm{N}$-th offshore station to the bay-mouth), the formula

$$
\begin{aligned}
\eta_{A}(t) & =a \eta_{A}(t-\tau)-b \eta_{A}(t-2 \tau)+c_{1}\left[F_{r}\right]_{1}\left(t-\tau-T_{1}\right) \\
& +c_{2}\left[F_{r}\right]_{2}\left(t-\tau-T_{2}\right)+\ldots+c_{7}\left[F_{r}\right]_{7}\left(t-\tau-T_{7}\right)
\end{aligned}
$$

in which subscripts $N=1,2, \ldots 7$ refer to station numbers, should have a pseudo-two-dimensional capacity to correlate the storm-tide $\eta_{A}(t)$ at the bay-mouth $\mathrm{A}$ with the offshore disturbances occuring over a wide area. The assumption here is that the local water level upheaval at any particular offshore station, created by a driving force $F_{r}\left(t-\tau-T_{N}\right)$, requires the interval of time $T_{N}$ to reach the bay-mouth and become merged in the resultant superelevation $\eta_{A}(t)$ occurring there.

This assumption actually follows a false premise insofar as it associates 'effect' (waves) with 'cause' (wind stress and pressure gradient) and translates the 'effect' instead of the 'cause' from station to bay-mouth. Thus $\mathrm{T}_{\mathrm{N}}$ should correctly be based on the time that the meteorological forcing function, $F_{r}$, directed radially to the bay-mouth, would take to travel the intervening distance, if its identity could be preserved. The value of, $T_{N}$, in other words, should be some function of the speed of the storm and not of the speed of the waves. If $T_{N}$ were to be determined rigorously it would require evaluation of the forcing function $F$ for each station as a continuous function of both $t$ and of $r$, the distance from the bay-mouth. The manual computing time that it would have required to do this would have been prohibitive so that some evasive tactics were necessary. The use of $\mathrm{T}_{\mathrm{N}}$ based on 'effect' seemed to offer the best way of circumventing the difficulty. 


\section{HURRICANE TIDE PREDICTION FOR NEW YORK BAY}

At first sight it may seem that unwarranted liberty is being taken with the physical structure of the solution given by Eq. (30). However it is a well known dynamical principle that, if $\omega / \mathrm{S}$, the forced-free frequency ratio of Eq. (22) is less than unity, the phase difference between cause and effect is relatively small. Hence for slow moving storms, at least, $T_{N}$ in Eq. (3I), based on the wave travel time, will be reasonably correct. Only when $\omega / \mathrm{S}$ approaches or exceeds unity, in the linear oscillating system we are dealing with, will $\mathrm{T}_{\mathrm{N}}$ become unreliable if founded on the wave travel time. The dynamics of the system suggest that a lag $\mathrm{T}_{\mathrm{o}}$ will result between cause and effect as indicated by Eqs. (17), (24) and (30). Since $T_{N}$ will give the effect at the bay-mouth we must therefore correct by a time $\mathrm{T}_{\mathrm{V}}$ in order to ensure that the cause will precede the effect by the necessary lead $T_{0}$. Thus it becomes necessary to rewrite Eq. (31) as

$$
\eta_{A}(t)=a \eta_{A}(t-\tau)-b \eta_{A}(t-2 \tau)+\sum_{i}^{N=7} c_{N}\left[F_{r}\right]_{N}\left(t-\tau-T_{N}+T_{V}\right)
$$

In the absence of the correction $\mathrm{T}_{\mathrm{V}}$ the functioning of $\mathrm{Eq}$. (31) is represented schematically in Fig. 3. The individual $F_{r}$ contributions from the different stations, at times earlier by $T_{N}$, converge along the radial distance-time paths to the point of time $(t-\tau)$ at station $A$, giving, in effect, the uncorrected function

$$
\sum_{1}^{N=7} c_{N}\left[F_{r}\right]_{N}\left(t-\tau-T_{N}\right)
$$

The gradients $\mathrm{dr} / \mathrm{dt}$ of the propagation lines in the $\mathrm{r}-\mathrm{t}$ plane (Fig. 3 ) are the velocities $\mathrm{C}=\sqrt{\mathrm{gd}}$ at which the free waves travel along the radial directions (Fig. 3, inset) over the variable depths of the shelf. The lag correction, $T_{V}$ that is required for fast moving storms will be $d$ is cussed further at a later stage.

\section{ALLOWANCE FOR THE GEOSTROPHIC EFFECT}

The influences of the earth's rotation enter into the dynamical equations in the terms involving the Coriolis parameter f [Eqs. (2)]. They are likely to be greatest in the relatively shallow water near the coast. In discussion of these effects it is convenient to consider the y-axis 
COASTAL ENGINEERING

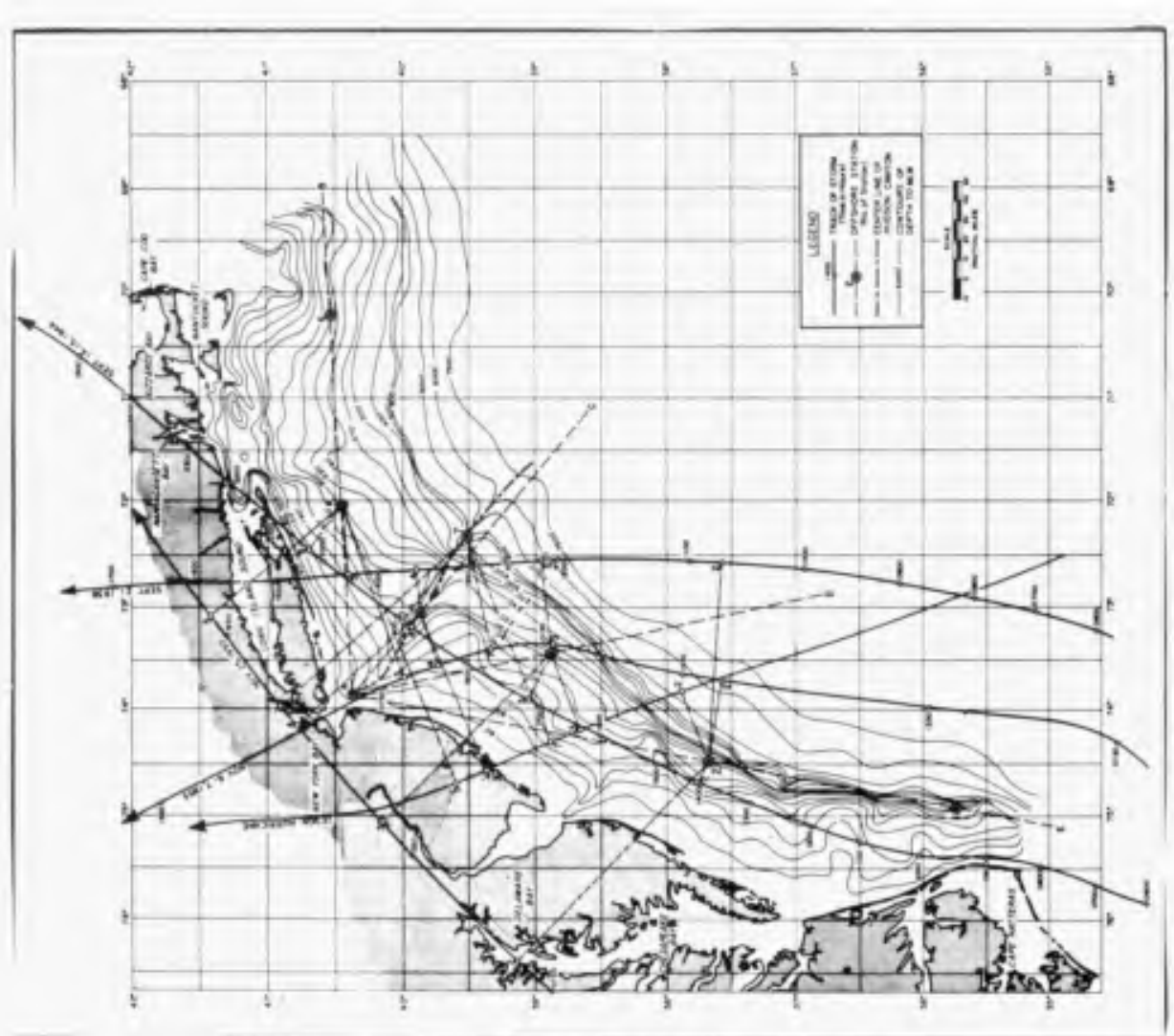

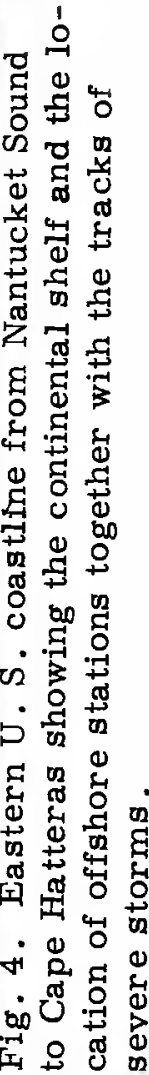

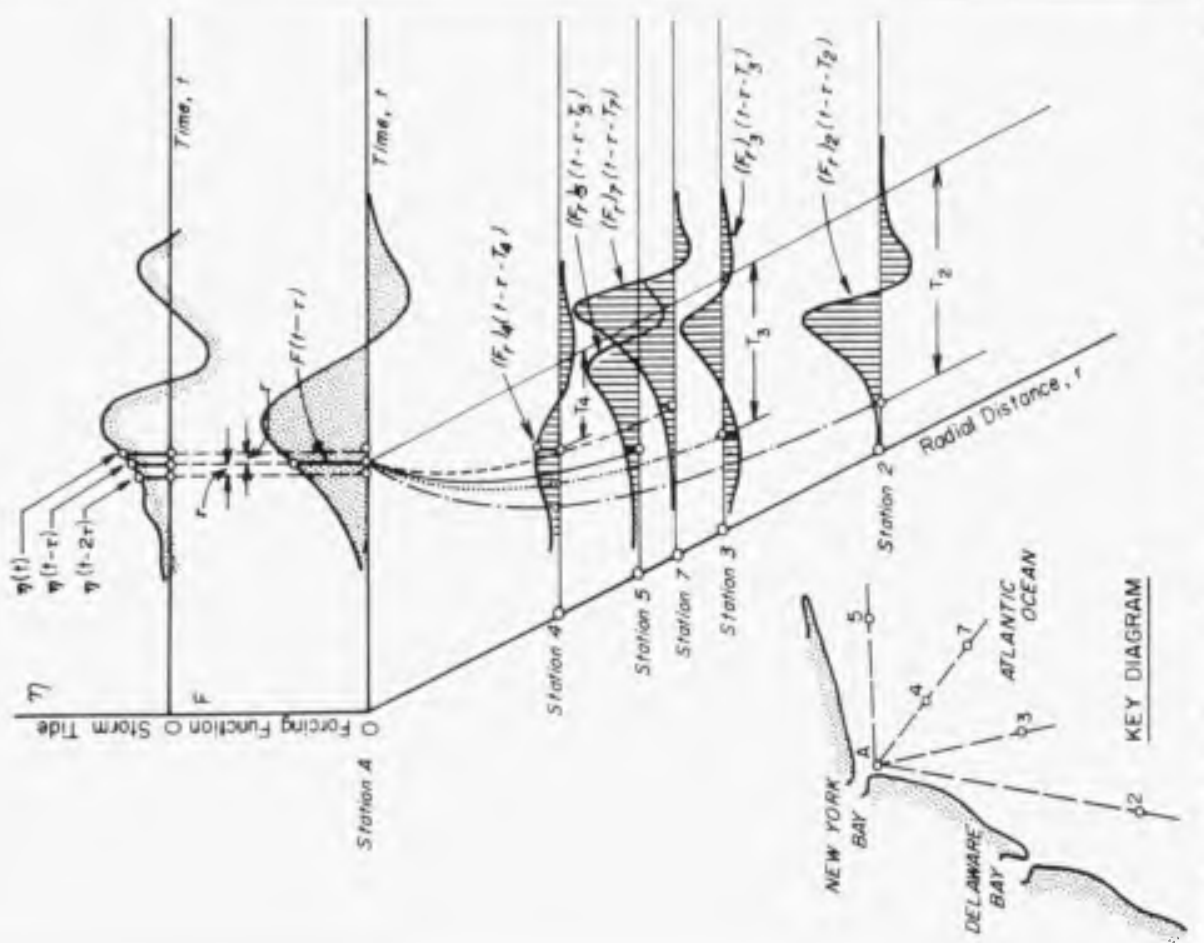

岁丢 总

嵒范

ษ.

.

녕 도웡

동휴 ․․

害嵒

C

崖。车

, 台员

告 雷

원

연

풍

텽뎡

ชั0 武

次

. 응

क न

so 


\section{HURRICANE TIDE PREDICTION FOR NEW YORK BAY}

of reference in Eqs. (2) as parallel to the coast and the $x$-axis normal thereto. Then, if we can assume that the flow onshore, $Q_{x}$, resulting from a superposed hurricane is appreciably less than the longshore flow, $Q_{y}$, because of the boundary effect, it is possibie to simplify Eqs. (2) by discarding $Q_{x}$ relative to $Q_{y}$. Further, available sources of information [ eg. Moore, 1957] suggest that the storm tide gradient alongcoast is very much less than it is normal to the coast, making it possible to approximate further by discarding $\frac{\partial \eta}{\partial y}$ in comparison with $\frac{\partial \eta}{\partial x}$. If these adjustments are made in Eqs. $(2, i)$ and $(2, i i)$ they reduce to

$$
\left.\begin{array}{l}
Q_{y}=\frac{1}{f}\left(g d \frac{\partial \eta}{\partial x}-F_{x}\right) \\
\left(\frac{\partial}{\partial t}+K\right) Q_{y}=F_{y}
\end{array}\right\}
$$

For the purposes of the further development of the correlation formula Eq. (30), it is convenient to neglect the damping effect of bottom friction, represented in the factor $K$ in Eqs. (33), and eliminate $Q_{y}$ between the two equations. There results

$$
\text { gd } \frac{\partial \eta}{\partial x}=\int f F_{t} d t+F_{n}
$$

in which $F_{n}\left(=F_{x}\right)$ and $F_{t}\left(=F_{y}\right)$ are respectively the normal $(n)$ and tangental ( $t$ ) components of the forcing functions [Eqs. (3)]. Eq. (34) compares with Eq. $(4, i)$ and it is thus of quasi-one-dimensional form, from which, by association, it is possible to extend Eq. (32) by addition of a term comparable to $\int f F_{t} d t$ in Eq. (34), to allow for the geostrophic effect.

This is most readily done by introducing the term

$$
c_{A} \sum_{t=0}^{t=n \tau}\left[F_{t}\right]_{A}(t-\tau)
$$

applicable to station $\mathrm{A}$ at the bay-mouth (Fig. 3 , inset). The cumulative summation of $\left(F_{t}\right)_{A}$ at increments of time $\tau$ is equivalent to the integral of $F_{t}$ with respect to time.

For the downcoast offshore station no, 2 (Fig. 3, inset), Eq. (34) suggests that the normal component, $F_{n}$, should be used in preference to $F_{r}$, the radial component of the driving forces, to describe the effect 


\section{COASTAL ENGINEERING}

induced there. Further since this effect must be allowed to travel along the radial line 2-A towards New York and this route is not far removed from parallelism with the coast, it is rational to base the travel time $T_{2}$ of the disturbance upon the edgewave speed peculiar to the shelf slope. In accordance with the finding of Stokes [Lamb, $1932 \mathrm{Edn} . \$ 260$ ] this velocity is

$$
C=\left[\frac{g s \lambda}{2 \pi}\right]^{\frac{1}{2}}
$$

in which $s$ is the shelf slope and $\lambda$ the wave length of the edgewaves. The choice of $\lambda$ will be discussed later.

\section{THE ADOPTED THEORETICO-EMPIRICAL CORRELATION-PREDICTION EQUATION}

As a final addition to Eq. (32) we include, besides the geostrophic term applicable at station $A$ at the bay-mouth, an equivalent pressure gradient term $\delta \mathrm{p}_{\mathrm{A}}\left(\mathrm{t}-\tau-\mathrm{T}_{\mathrm{o}}\right)$ additional to $\left(\mathrm{F}_{\mathrm{r}}\right)_{\mathrm{A}}\left(\mathrm{t}-\tau-\mathrm{T}_{\mathrm{o}}\right)$ such that

$$
\delta \mathrm{p}_{\mathrm{A}}\left(\mathrm{t}-\tau-\mathrm{T}_{\mathrm{o}}\right)=\left(\mathrm{p}_{\mathrm{a}}\right)_{\mathrm{A}}\left(\mathrm{t}-\tau-\mathrm{T}_{\mathrm{o}}\right)-\mathrm{p}_{\mathrm{o}}\left(\mathrm{t}-\tau-\mathrm{T}_{\mathrm{o}}\right)
$$

where $\left(\mathrm{pa}_{\mathrm{A}}\right)_{\mathrm{A}}$ is the atmospheric pressure at $\mathrm{A}$ and $\mathrm{p}_{0}$ the central pressure in the eye of the storm at the same instant. Also, for the purposes of satisfactory correlation, it is desirable to introduce an independent coefficient $c_{0}$.

The final formulation then of a correlation and prediction equation for storm tides in New York Bay includes the terms (35) and (37), but rejects , as too remote for consideration, the influences from offshore stations 1 and 6 (see Fig. 4, post). The formula as finally used (and found to be successful is thus

\footnotetext{
* Earlier versions originally included effects of stations 1 and 6.
} 


$$
\begin{aligned}
\eta_{A}(t) & =a \eta_{A}(t-\tau)-b \eta_{A}(t-2 \tau)+c_{o}+c_{A 1} \delta p_{A}\left(t-\tau+T_{V}\right) \\
& +c_{A 2} \sum_{t=0}^{t=n \tau}\left[F_{t}\right]_{A}\left(t-\tau+T_{V}\right)+c_{A 3}\left[F_{r}\right]_{A}\left(t-\tau+T_{V}\right) \\
& +c_{2}\left[F_{n}\right]_{2}\left(t-\tau+T_{V}-T_{2}\right)+c_{3}\left[F_{r}\right]_{3}\left(t-\tau+T_{V}-T_{3}\right) \\
& +c_{4}\left[F_{r}\right]_{4}\left(t-\tau+T_{V}-T_{4}\right)+c_{5}\left[F_{r}\right]_{5}\left(t-\tau+T_{V}-T_{5}\right) \\
& +c_{7}\left[F_{r}\right]_{7}\left(t-\tau+T_{V}-T_{7}\right)
\end{aligned}
$$

\section{AVAILABLE WIND AND PRESSURE DATA FOR EAST COAST STORMS}

Data packages for selected storms were compiled by the Weather Bureau and furnished to the project. These contained maps of storm tracks, isotachs of surface wind velocity, isobars of surface pressure, profiles of pressure and deflection angles of wind direction (in the case of hurricanes). The packages embraced the following storms:

(a) Hurricane of September 21, 1938

(b) Hurricane of September 14, 1944

(c) Extratropical Storm of November 24-25, 1950

(d) Extratropical Storm of November 6-7, 1953.

In addition a similar data package was supplied in respect of a Design Hurricane based on the 1938 hurricane, transposed to a new track crossing the East Coast approximately at Atlantic City. The tracks of these several storms are shown in Fig. 4 and provide good overall representation of possible approach directions of severe storms to the New York area. The track of the 1938 hurricane for instance runs almost due north, emerging from the South over deep water before crossing Long Island and the New England coast almost at right angles. In contrast, the 1944 hurricane track parallels the east coast, north of Cape Hatteras, and lies well within the confines of the continental shelf. The extratropical storm of 1950 was centered overland on a path roughly parallel with the smoothed trends of the east coast, while that of 1953 runs approximately due north over deep water and curves to the north-west over the continental shelf to pass directly through the portals of New York Bay. 

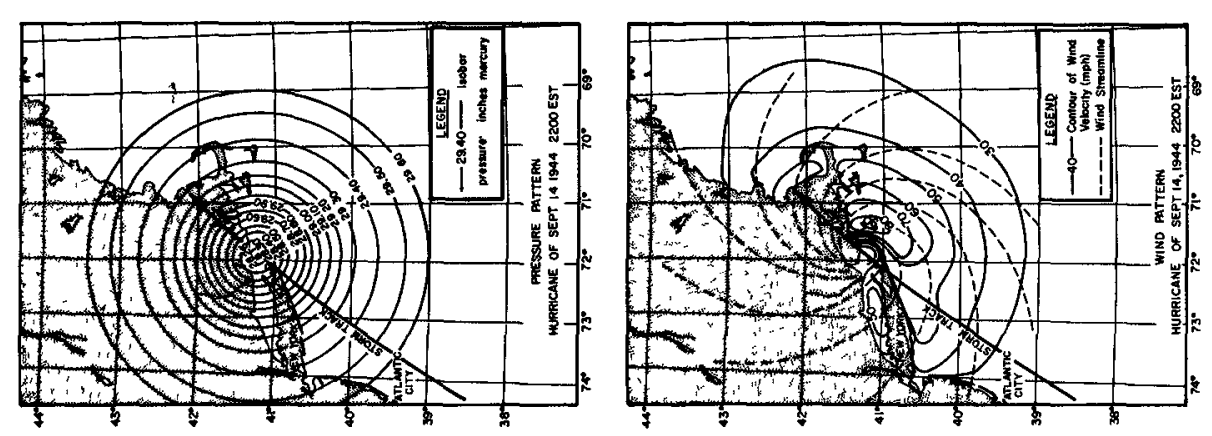

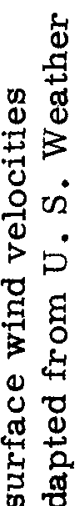
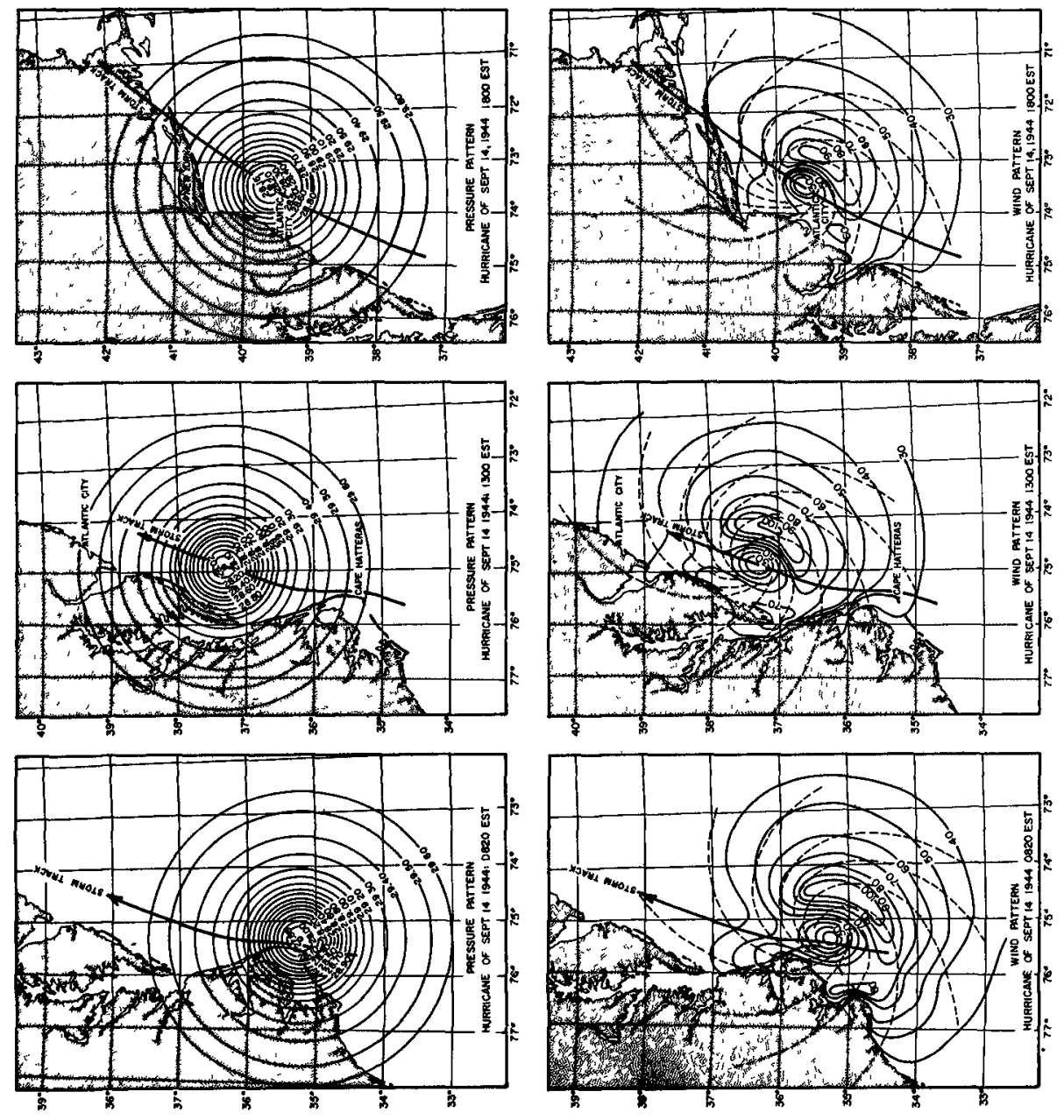

రृ

ชี .

\&

क

을

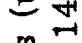

on

8

on

宫

का ए

.

3

臬

on

م.

韋

일

응

尔造

药

पै

00

号

w

뎡

记荹

i

मृ

占垈

564 
HURRICANE TIDE PREDICTION FOR NEW YORK BAY
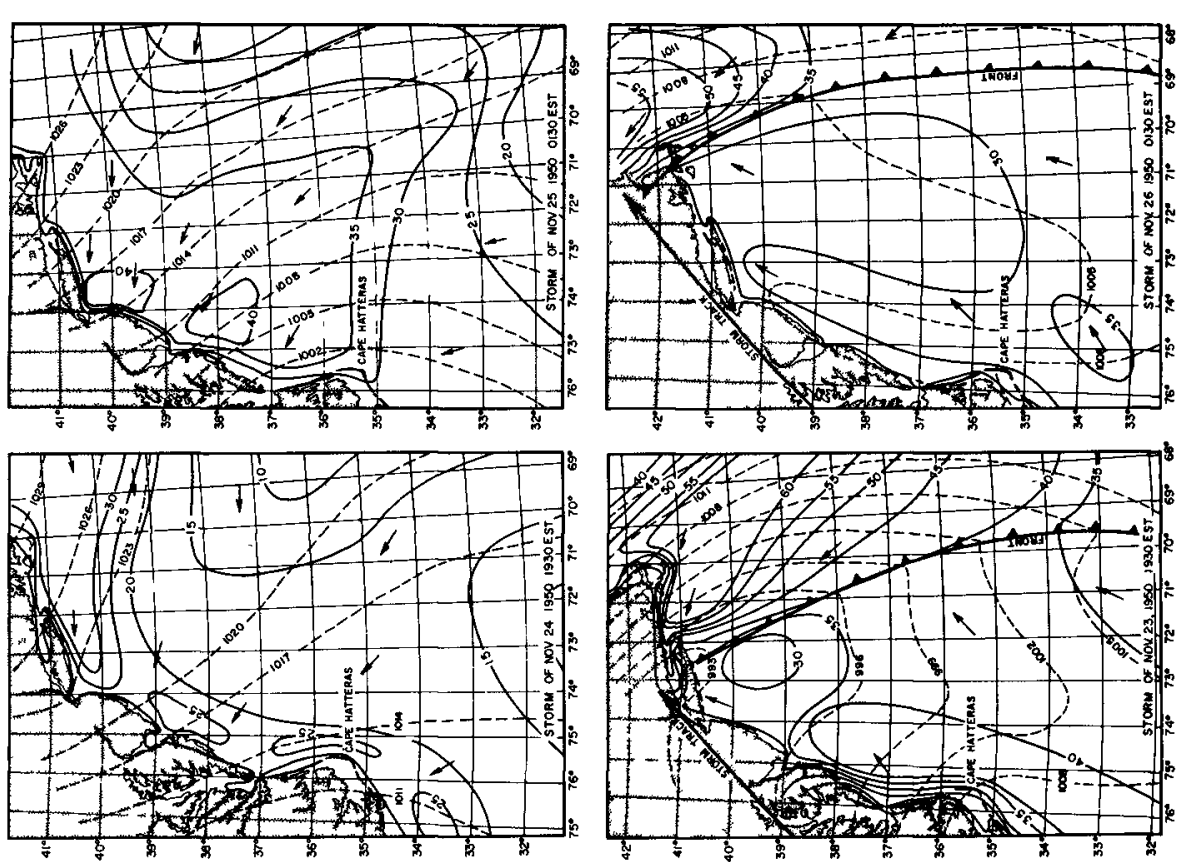

.
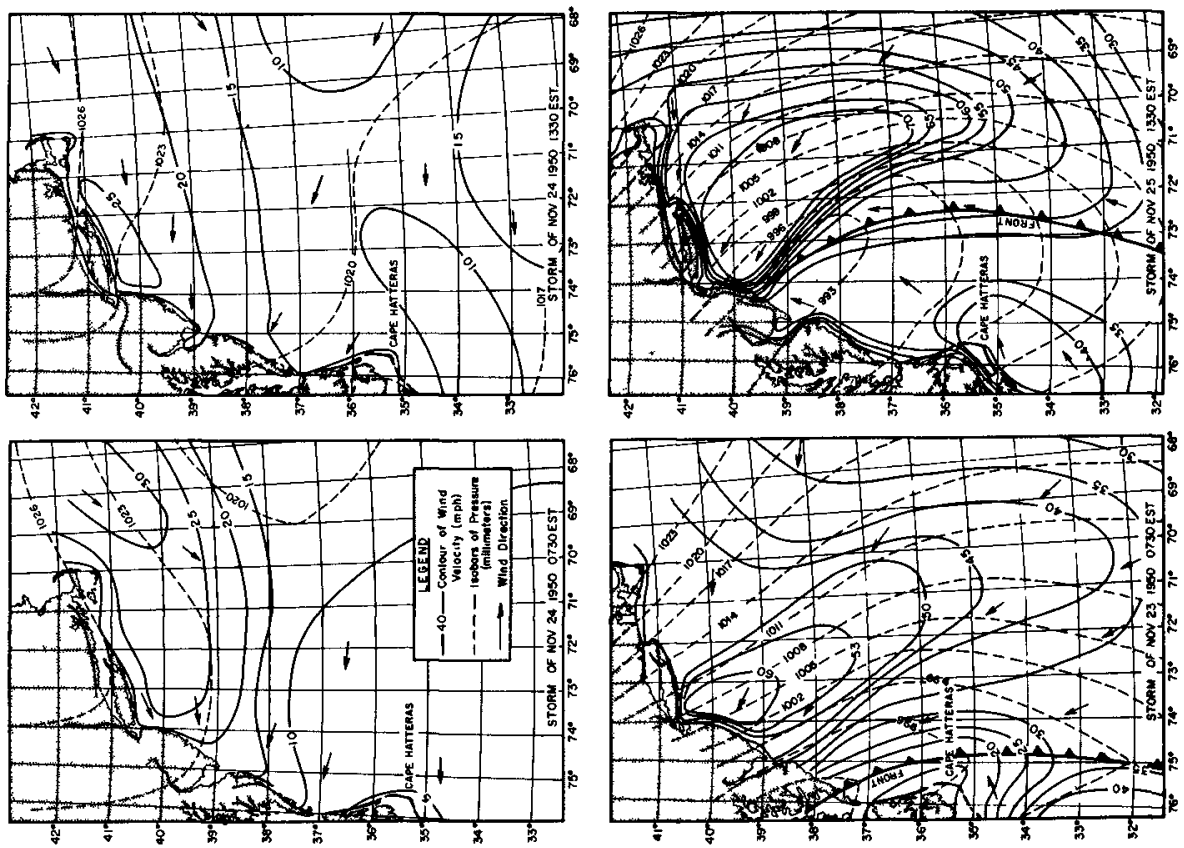

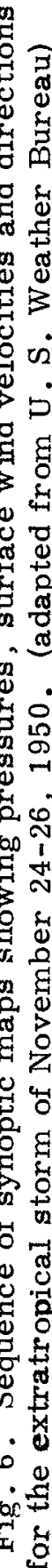

565 


\section{COASTAL ENGINEERING}

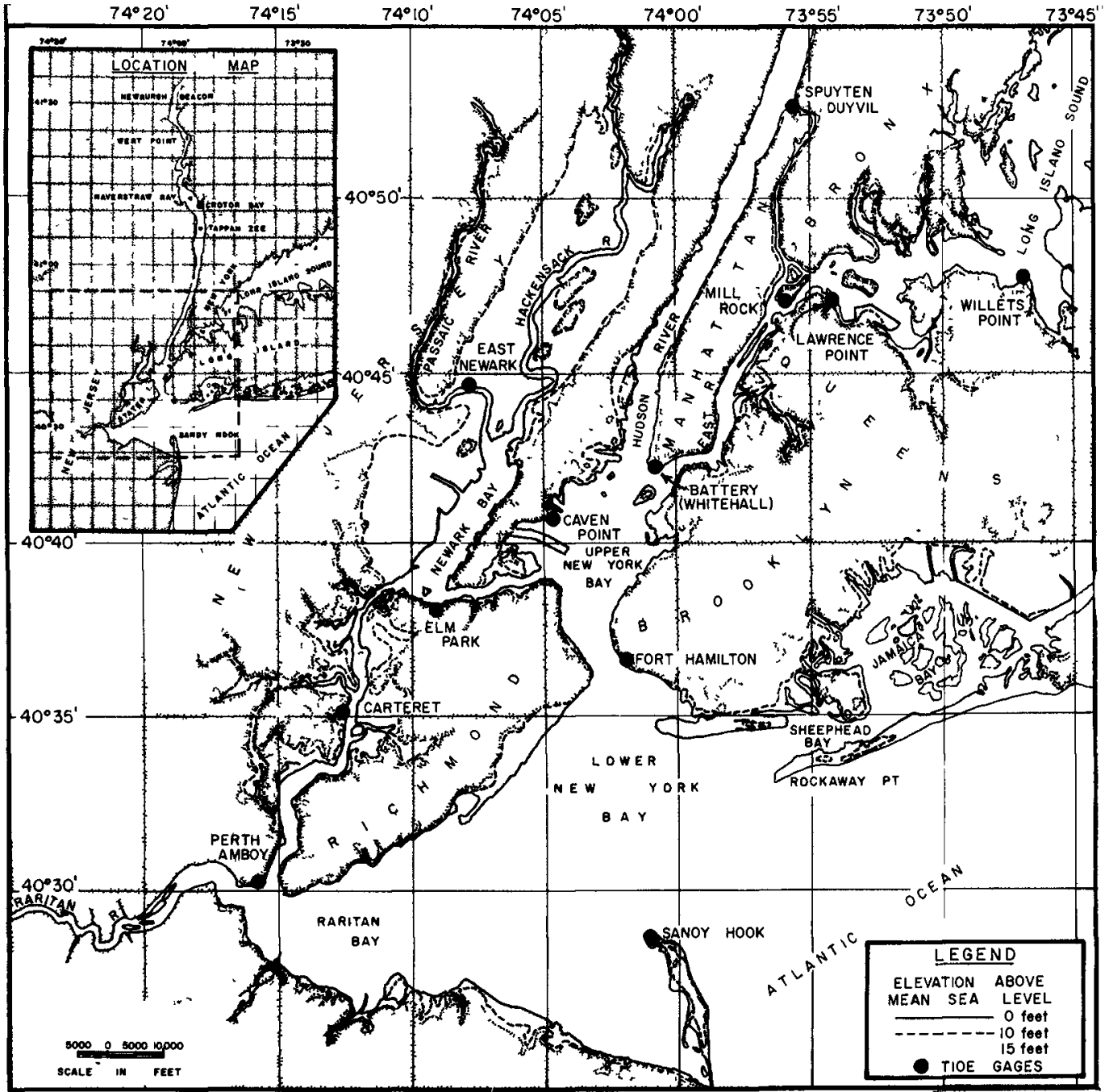

Fig. 7. Map of New York Bay and River System showing locations of gaging stations and low-lying land areas. 

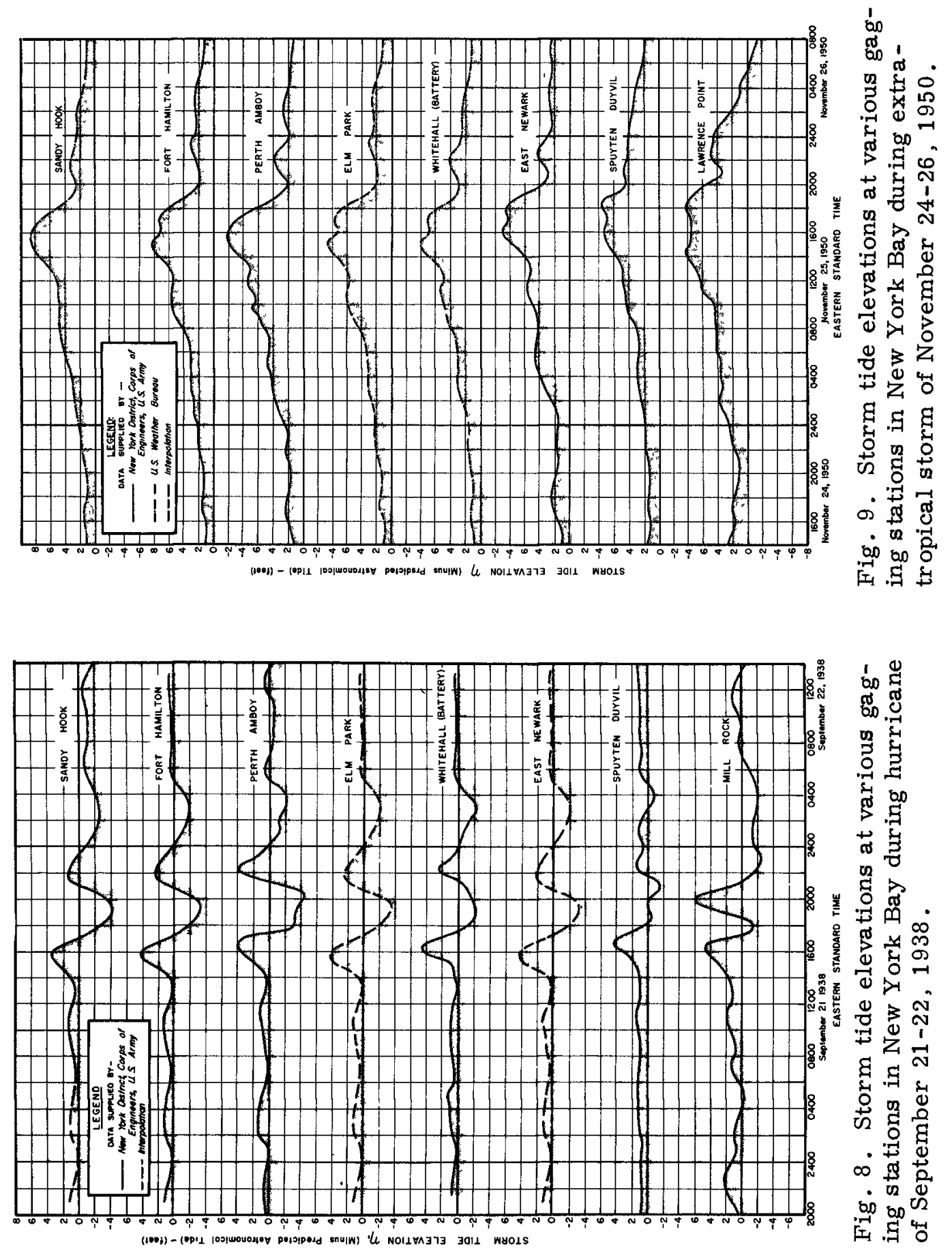


\section{COASTAL ENGINEERING}

In Figs. 5 and 6 are recorded the main features of the surface pressure and wind distributions in two of these storms, as adapted from the data packages It may be remarked from Fig. 5 that the 1944 hurricane was traveling at conside able speed ( $\mathrm{cf}$ the order of 40-50 knots) over the continental shelf before strikir the coast. The 1938 hurricane moved at roughly comparable velocities. The 19 and 1953 storms were very much slower-moving and it is not surprising that the accumulations of water piled by them into New York Bay and its river system exceeded in volume those from the more transient hurricanes of 1938 and 1944.

\section{OBSERVED WATER LEVELS AT GAGING STATIONS IN NEW YORK BAY}

Tide gage stations at which water levels are regularly recorded through out New York Bay are shown in Fig. 7. From the tidal records of these stations predicted astronomical tides for the storm periods in question were deducted leaving residual meteorological tides of which Figs. 8 and 9 , as applicable to the 1938 hurricane and the 1950 extra-tropical storm respectively, are typical. The figures show the histories of storm tide elevation at eight of the gaging stations within New York Bay (cf Fig. 7).

The somewhat striking differences between the storm tides created by the 1938 and 1944 hurricanes and those raised by the slow-moving storms of 1950 and 1953 are quite typically portrayed by the differences between Figs. 8 and 9 . The elevations at Sandy Hook may be considered representative of $\eta_{A}(t)$ in Eq. (38).

The hurricane effects are characterized by low antecedent waves followec by the main surge, which, as noted by Redfield and Miller [1956], tends to have a more rapid descent than ascent. After the main surge follow from two to three (or more) resurgences at approximately regular intervals, which on the average are considered to be of 7 hours period (Redfield and Miller, 7.2 hours). The storm tides induced by the 1950 and 1953 storms (cf Fig. 9) show a very much more gradual ascent and are obviously more consonant with the steady state conception of water super-elevation or 'set-up'. Resurgences, though identifiable, are also much less prominent.

As might be expected, water level behavior at Mill Rock (Fig. 7) is considerably influenced by the channel flow from Long Island Sound. In Fig. 8 the first surge at Mill Rock is obviously that caused by penetration of the storm tide up the East River, but the second (higher) surge, occurring earlier than the resurgences anywhere else in the bay, must represent the surge wave that has reached Mill Rock via Long Island Sound. A somewhat similar effect is found in respect of the influence of the 1944 hurricane at Mill Rock. These peculiarities of the transient hurricanes are largely absent in Fig. 9, representative of the slc extratropical storms. 


\section{HURRICANE TIDE PREDICTION FOR NEW YORK BAY}

\section{REDUCTION AND APPLICATION OF DATA}

In order to apply Eq. (38) it was necessary to evaluate the forcing functions, $F$, at the different offshore stations, which were selected in the positions shown in Fig. 4.

The values of $\mathrm{F}_{\mathrm{r}}$, the resolved part of $\mathrm{F}$ in the particular direction $\phi$ of the bay-mouth, with respect to the $x$-axis of reference (Fig. 10), are given by

$$
\begin{aligned}
& \text { (i) } F_{r}=F \cos (\phi-\theta) \\
& \text { (ii) } F=\sqrt{F_{x}^{2}+F_{y}^{2}} \\
& \text { (iii) } \tan \theta=\frac{F y}{F_{x}}
\end{aligned}
$$

where $\theta$ is the bearing of $F$, the resultant of $F_{x}$ and $F_{y}$ of Eqs. (3), taken anti-clockwise with reference to the $\mathrm{x}$-axis.

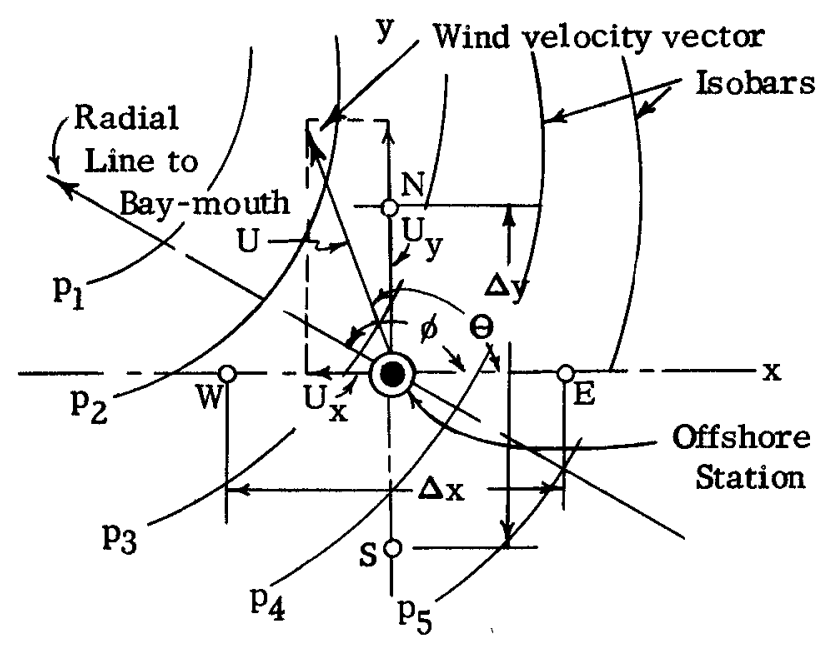

Fig. 10: Measurement of $\mathrm{x}$ and $\mathrm{y}$ components of velocities and surface pressure-gradients at an offshore station. 

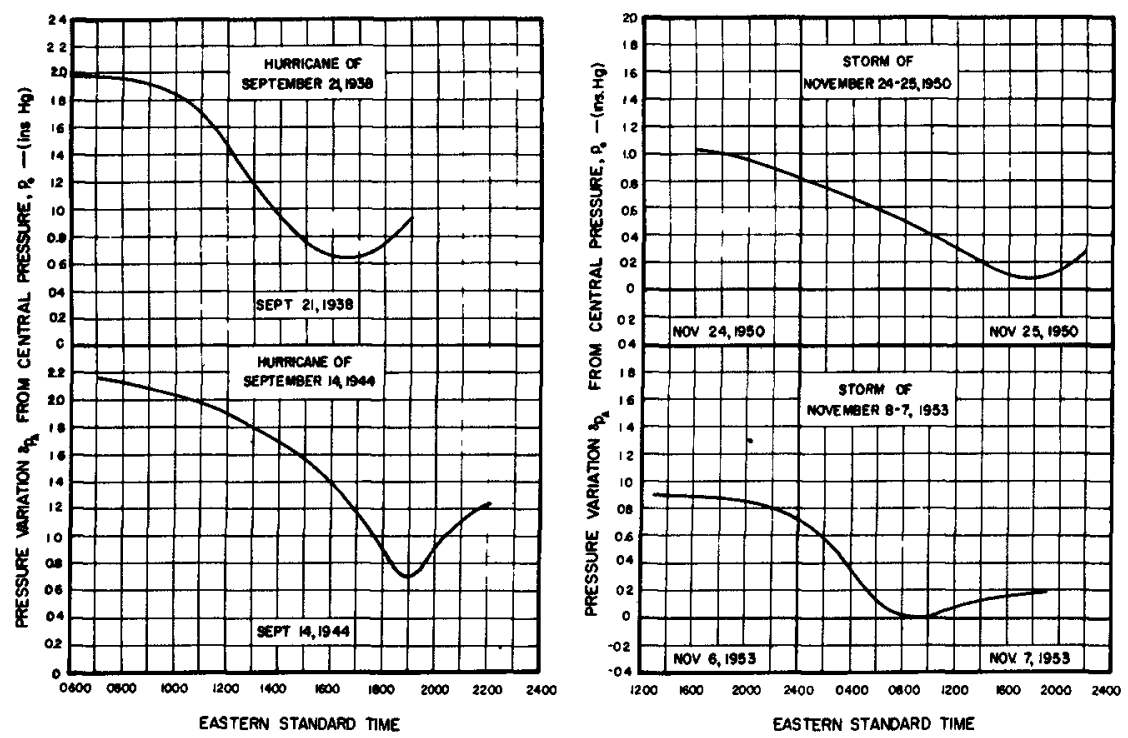

Fig. 11. Values of forcing function $\delta$ pA (for station $A$ at mouth of New York Bay) for the four reference storms of 1938, 1944, 1950 and 1953 .

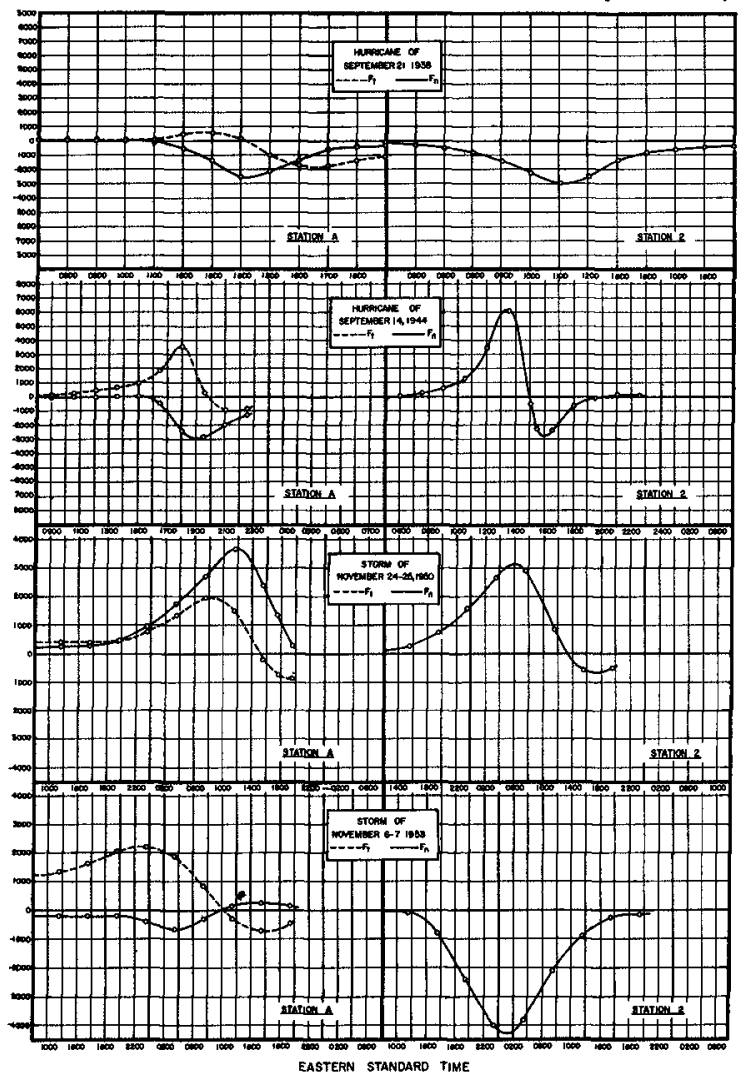

Fig. 12. Values of forcing functions $F_{n}(t)$ and $F_{t}(t)$ (for stations $A$ and 2 ) for the four reference storms of $1938,1944,1950$ and 1953 . 


\section{HURRICANE TIDE PREDICTION FOR NEW YORK BAY}
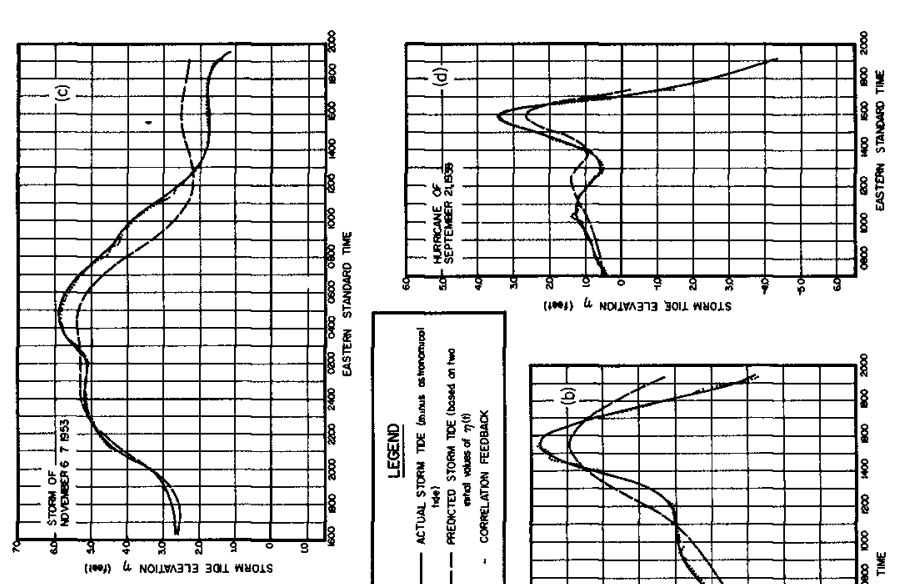

照

ซี

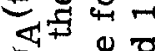
$=$

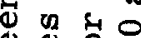

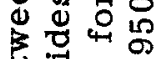

焉峾

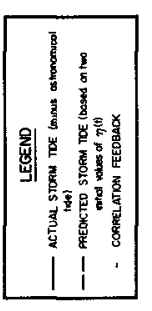

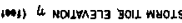

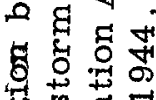

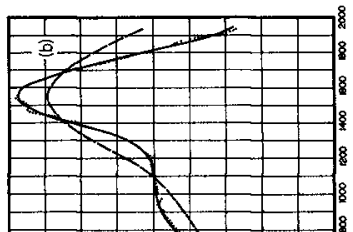

I o o w

\%

$4+\overrightarrow{0} \gg \sigma$

है न

0 व

岁题

$\rightarrow \square$ व

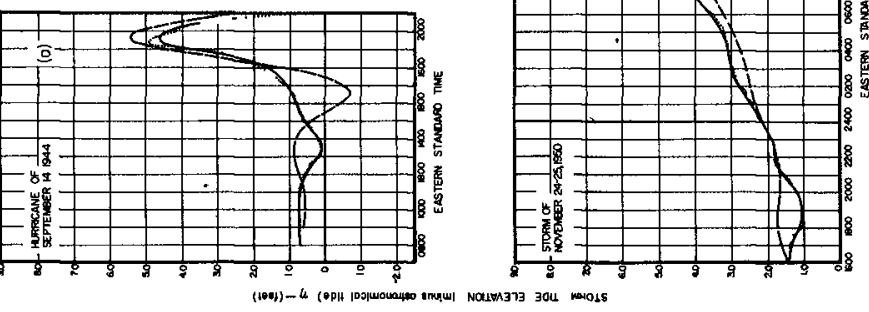

政 ชี สี

- $\begin{gathered}0 \\ 0\end{gathered}$

†i

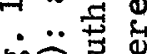

50 更 压毛

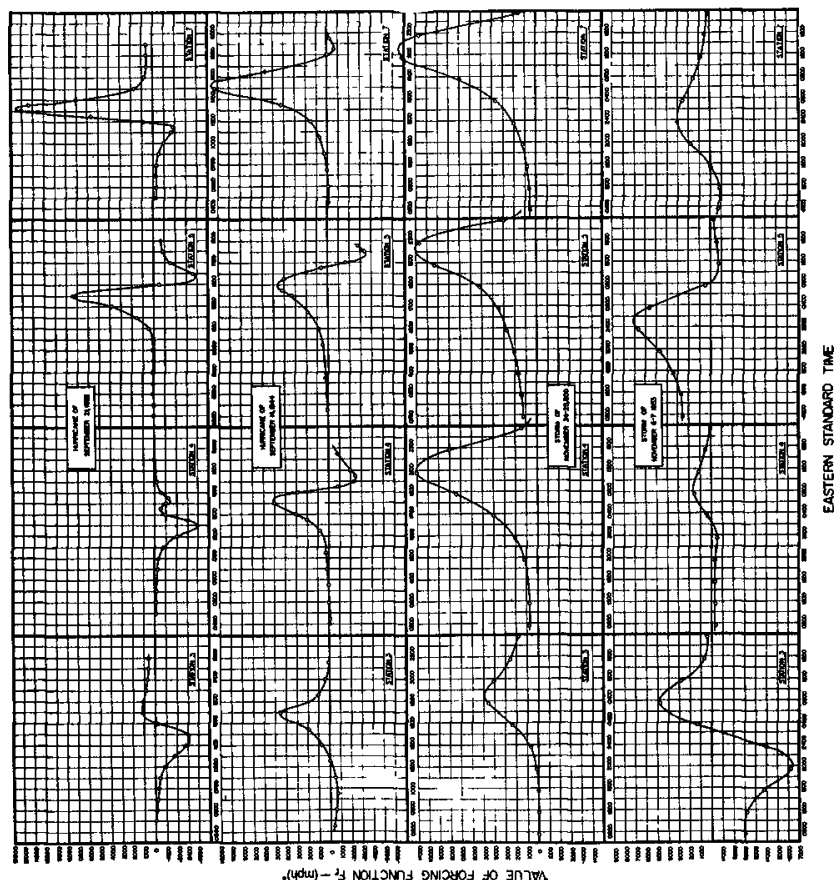

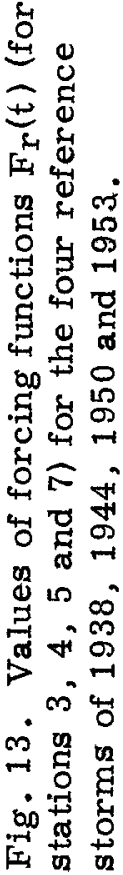


Eqs. (3) for $F_{x}$ and $F_{y}$ may be reduced to the form

$$
\left.\begin{array}{l}
\text { (i) } \mathrm{F}_{\mathrm{x}}=\mathrm{k}\left[\mathrm{UU}_{\mathrm{x}}-\frac{\mathrm{d}}{\mathrm{k} \rho} \frac{(\Delta \mathrm{p})_{\mathrm{x}}}{\Delta \mathrm{x}}\right] \\
\text { (ii) } \mathrm{F}_{\mathrm{y}}=\mathrm{k}\left[\mathrm{U} \mathrm{U}_{\mathrm{y}}-\frac{\mathrm{d}}{\mathrm{k} \rho} \frac{(\Delta \mathrm{p})_{\mathrm{y}}}{\Delta \mathrm{y}}\right]
\end{array}\right\}
$$

where $U_{x}$ and $U_{y}$ are the $x$ and $y$ components respectively of the surface wind velocity $U$ at a station, $k$ is a constant in the wind stress relationship $\tau=\mathrm{k} \mathrm{U}^{2},(\Delta \mathrm{p})_{\mathrm{X}}$ and $(\Delta \mathrm{p})_{\mathrm{y}}$ are the differential pressure changes over the distances $\Delta x, \Delta y$ respectively, (Fig. 10), which are small in relation to the scale of the storm. The value of $\mathrm{k}$ taken as applicable to strong wind conditions was $3.1 \times 10^{6}$ [cf, Wilson, 1960].

To obtain $F_{n}$ at station 2 [cf Eq. (38)], the angle $\phi$ in Eq. (39i) was arranged to make the direction of the forcing function vector normal to the aver age direction of the coastline between station 2 and the bay-mouth. Again $F_{t}$ at station $\mathrm{A}[\mathrm{Eq} .(38)]$ was obtained by choosing $\phi$ to make the forcing function vector at right angles to the radial line CA (Fig. 4). Finally, the values of $\delta p_{A}$ were evaluated directly from Eq. (37) without difficulty.

Typical of the trends of the forcing functions for the four reference storms are the results shown in Figs. 11,12 and 13 .

\section{COEFFICIENT VALUES FOR PAST-TIME $\eta$-TERMS IN CORRELATION FORMUI}

As a convenient time increment for numerical correlation between $\left[\eta_{A}(t)-a \eta_{A}(t-\tau)+b \eta_{A}(t-2 \tau)\right]$ and the forcing functions in Eq. (38), $\tau$ was selected as 20 mins or $1 / 3$ hour. The period of resurgences has already been noted as being of the order of 7 hours (cf.Fig. 8), a period which can also be justified theoretically as being the fundamental natural period of oscillation of the ocean on the continental shelf off New York [Kajiura, 1959]. Accordingly $S$ in Eq. ( $14 \mathrm{i})$ has a value $(2 \pi / \mathrm{T})$ of 0.898 radians $/ \mathrm{hr}$. From examination of the resurgences of the 1938, 1944 and other hurricanes that have affected New York the conclusion was reached that the oscillations decay with an amplitude ratio, $e^{-(K T) / 2}$, per cycle, of about 0.5 , in agreement with an observation of Redfield and Miller [1956]. From this the damping factor $K$ is found to be $0.198(\mathrm{hr})^{-1}$. The values of $\mathrm{a}$ and $\mathrm{b}$, defined by Eqs. (14), are accordingly 


\section{HURRICANE TIDE PREDICTION FOR NEW YORK BAY}

$$
\begin{aligned}
& a=1.850 \\
& b=0.937
\end{aligned}
$$

which duly satisfy the stability requirements of Eqs. (16).

14. TRAVEL TIMES OF FREE WAVES FROM OFFSHORE STATIONS TO BAY-MOUTH

The travel time, $\mathrm{T}_{\mathrm{N}}$, taken by a free, long gravity wave to travel at speed $\mathrm{C}(=\sqrt{\mathrm{gd})}$ from any station $\mathrm{N}(=1,2 \ldots .7)$ to the bay-mouth at A can be computed from

$$
\mathrm{T}_{\mathrm{N}}=\int_{\mathrm{A}}^{\mathrm{N}} \frac{\mathrm{dr}}{\sqrt{\mathrm{gd}}}
$$

in which the depth $\mathrm{d}$ is a function of radial distance $\mathbf{r}$, in accordance with the nature of the shelf topography (Fig. 4). Numerical integration of Eq. (42) establishes the following values of $T_{N}$.

\section{TABLE I: TRAVEL TIMES OF FREE WAVES}

\begin{tabular}{c|c|c|c}
\hline \multirow{2}{*}{$\begin{array}{c}\text { Station No. } \\
N\end{array}$} & $\begin{array}{c}\text { Distance } \\
\mathrm{r} \\
\text { (naut. mi.) }\end{array}$ & \multicolumn{2}{|c}{ Time, $\mathrm{T}_{\mathrm{N}}$-(hours) } \\
\cline { 2 - 4 } & & Eq. (42) & Adopted Value \\
\hline \hline & 169 & 5 & $3-1 / 3^{*}$ \\
3 & 95 & $2-2 / 3$ & $2-2 / 3$ \\
4 & 50 & $1-1 / 4$ & $2-1 / 3$ \\
5 & 88 & $2-1 / 3$ & 2 \\
7 & 92 & 2 & \\
\hline \hline
\end{tabular}

The asterisked figure of $T_{2}=3-1 / 3$ hrs is the travel time for a longshore edgewave to cover the distance from station 2 to station $A$. Since the 
wave length $\lambda$ in Eq. (36) is expressible as $\lambda=\mathrm{CT}$, where $\mathrm{T}$ is the edgewave period, elimination of $\lambda$ in Eq. (36) yields an edgewave speed of

$$
C=\left(\frac{g s}{2 \pi}\right) T
$$

The average uniform shelf slope, $s$, normal to the coastline between stations 2 and $A$ is 1 in 1500 . By assuming that the resurgence period of 7 hours is also a manifestation of edgewaves [cf Munk, Snodgrass and Carrier, 1956] the travel time of the waves at the speed of $86.4 \mathrm{ft} / \mathrm{sec}[\mathrm{Eq} .(43)]$ is $3-1 / 3 \mathrm{hrs}$

\section{LEAST SQUARES DETERMINATION OF COEFFICIENTS $\mathbf{c}_{\mathrm{N}}$, AND LAG CORRECTIONS, $\mathrm{T}_{\mathrm{V}}$}

With $a, b$ and $T_{N}$ known, along with the time histories of $\eta_{A}(t)$ and the forcing functions at each offshore station, for each of the four reference storms, all the necessary data are on hand for conducting a multiple regression correlation for determination of the most appropriate values of the coefficients $\mathrm{c}_{\mathrm{N}}$ and the lag $\mathrm{T}_{\mathrm{V}}$ in Eq. (38). For lack of space the mechanics of this corr lation will not be discussed here since they are fairly routine numerical operations in high speed digital computing.

The data from the four reference storms were pooled to provide a total of 237 equations involving the unknown coefficients, $c_{N}$. For both the slow moving storms of 1950 and 1953, TV was taken zero, as justified in Section 7. The values of $\mathrm{T}_{\mathrm{V}}$ for the fast moving hurricanes of 1938 and 1944 had to be determined by successive approximations based initially on intelligent guesses; thus, specific values of $\mathrm{T}_{\mathrm{V}}$ had to be assumed in order to perform any least squares determination of the best fit values of the coefficients, $c_{N}$.

Each time a correlation was run, a simple feed-back operation, in which $\eta_{A}(t)$ was computed from Eq. (38) by making use of the true, known values of $\eta_{A}(t-\tau)$ and $\eta_{A}(t-2 \tau)$, gave a general check on the correctness of the overall procedure. Such a feed-back is indicated by the chain-dot curves in Fig. 14 which invariably compared favorably with the actual (full-1ine) storm tides. The real test of adequacy of the correlation results came from the use in Eq. (38) of the coefficients $c_{N}$ together with the assumed values of $T_{V}$ (for the 1938 and 1944 hurricanes), starting with just two initial values of $\eta_{A}(t-\tau)$ and $\eta_{A}(t-2 \tau)$. These starting values were taken identical with the actual storm tide elevation at $t=0$ for each storm. From then on, - for example, at the very next time-step of $\tau=1 / 3 \mathrm{hr}$, - the computation was entirt 
dependent on its own predicted values of $\eta_{A}(t)$, which had to be successively fed into the right-hand side of Eq. (38).

Fig. 14 shows the predicted storm tides (dash-line curves) calculated in this manner for the values of $c_{N}$ and $T_{V}$, as finally adopted. The bestfit values of the lag correction $T_{V}$ were found to be 1.67 and $1.33 \mathrm{hrs}$ for the 1938 and 1944 hurricanes respectively. The values of $c$ in Eq. (38) (yielding an overall correlation coefficient of 0.89 ) were as follows:

$\left.\begin{array}{lll}c_{0} & =10074576 & 49^{*} \\ c_{A 1}=29460220 & 48- \\ c_{A 2}=14493105 & 44 \\ c_{A 3}=27135231 & 45 \\ c_{2}=24016580 & 45- \\ c_{3}=38117168 & 45- \\ c_{4}=51729379 & 45 \\ c_{5}=40529138 & 45 \\ c_{7}=47817714 & 44-\end{array}\right\}$

The predictions shown in Fig. 14 for each of the four reference storms were considered to be in sufficiently good agreement with the actual storm tides to justify the use of Eq. (38), together with the coefficient values of (44), in application to any other storm in the New York Bay area, regardless of its nature, direction and velocity of approach. The formula was therefore applied to several design hurricanes.

\section{PREDICTED DESIGN-HURRICANE STORM TIDES}

The design-hurricane to be discussed here (one of several for which computations have been made) was quite similar to the 1938 hurricane but its path was transposed to a new track (Fig. 4), likely to bring more severe effects to bear on New York. The pressure and wind patterns for this storm are shown in Fig. 15.

This number indicates the position of the decimal point according to the IRM floating point classification in the Bell system. Thus for 49 , $c_{0}=0.10074576 ;$ for $45, c_{2}=-0.000024016580$. 

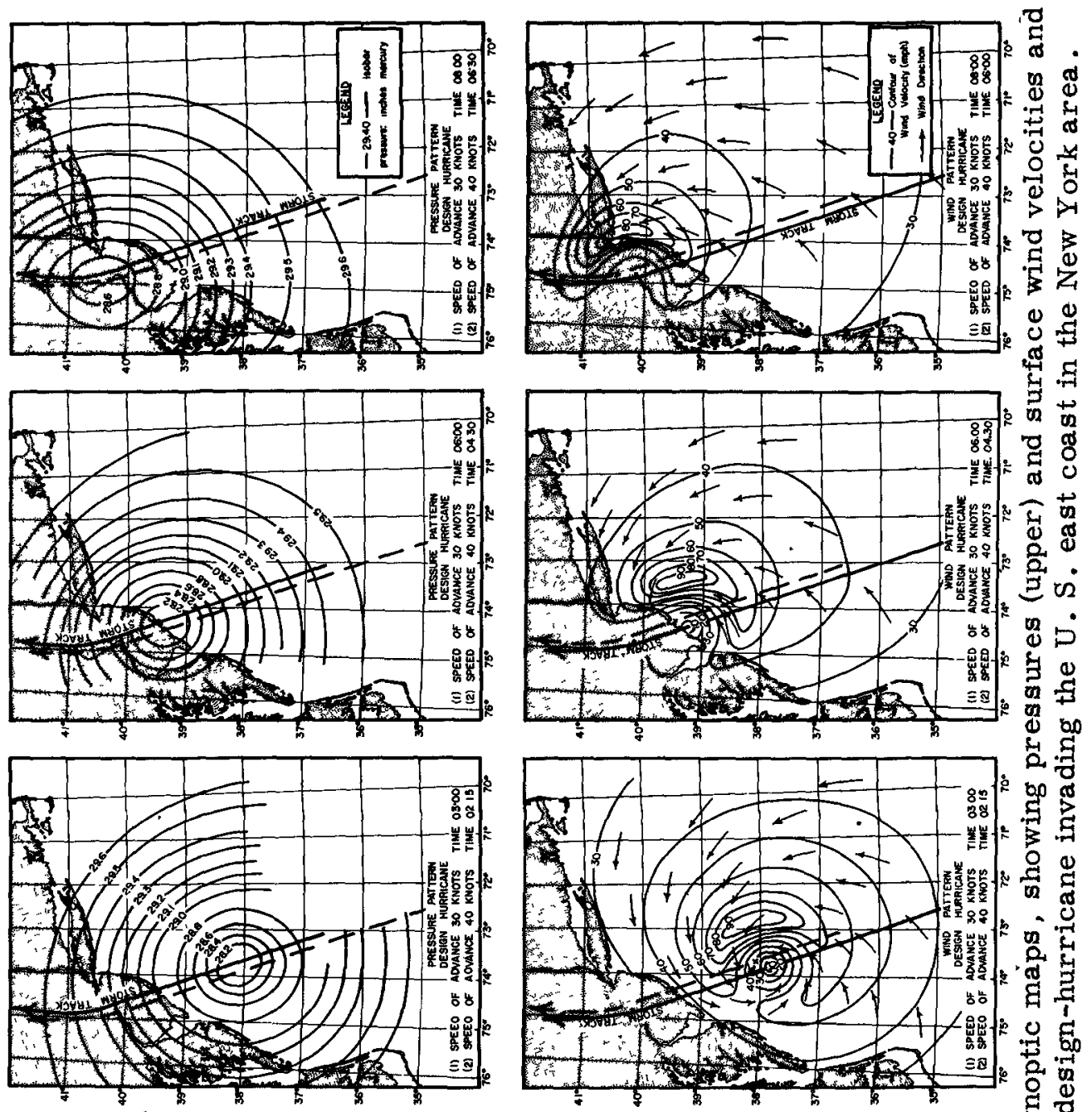

돔.
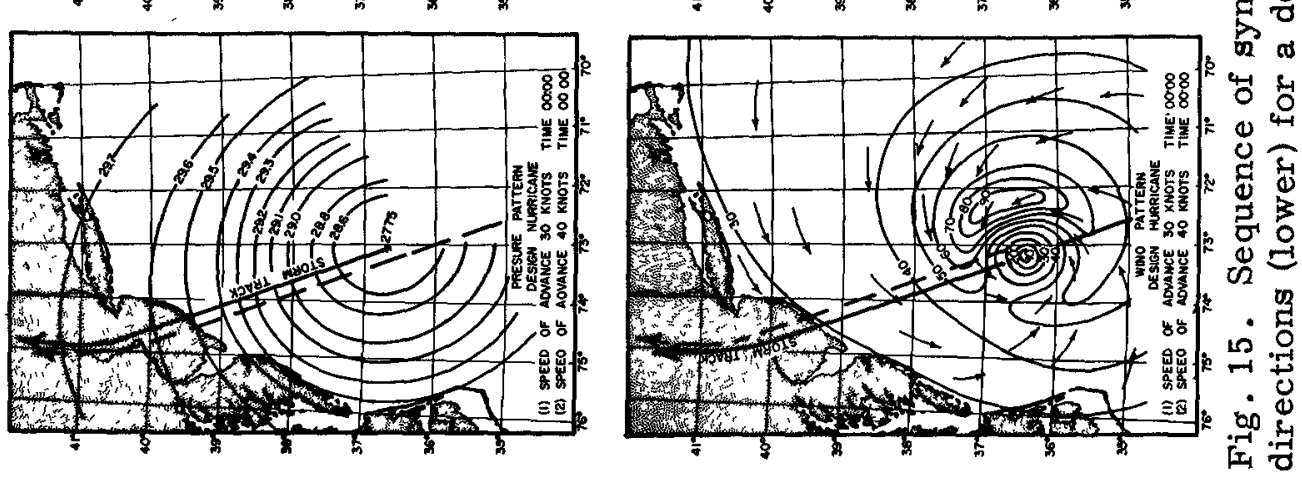

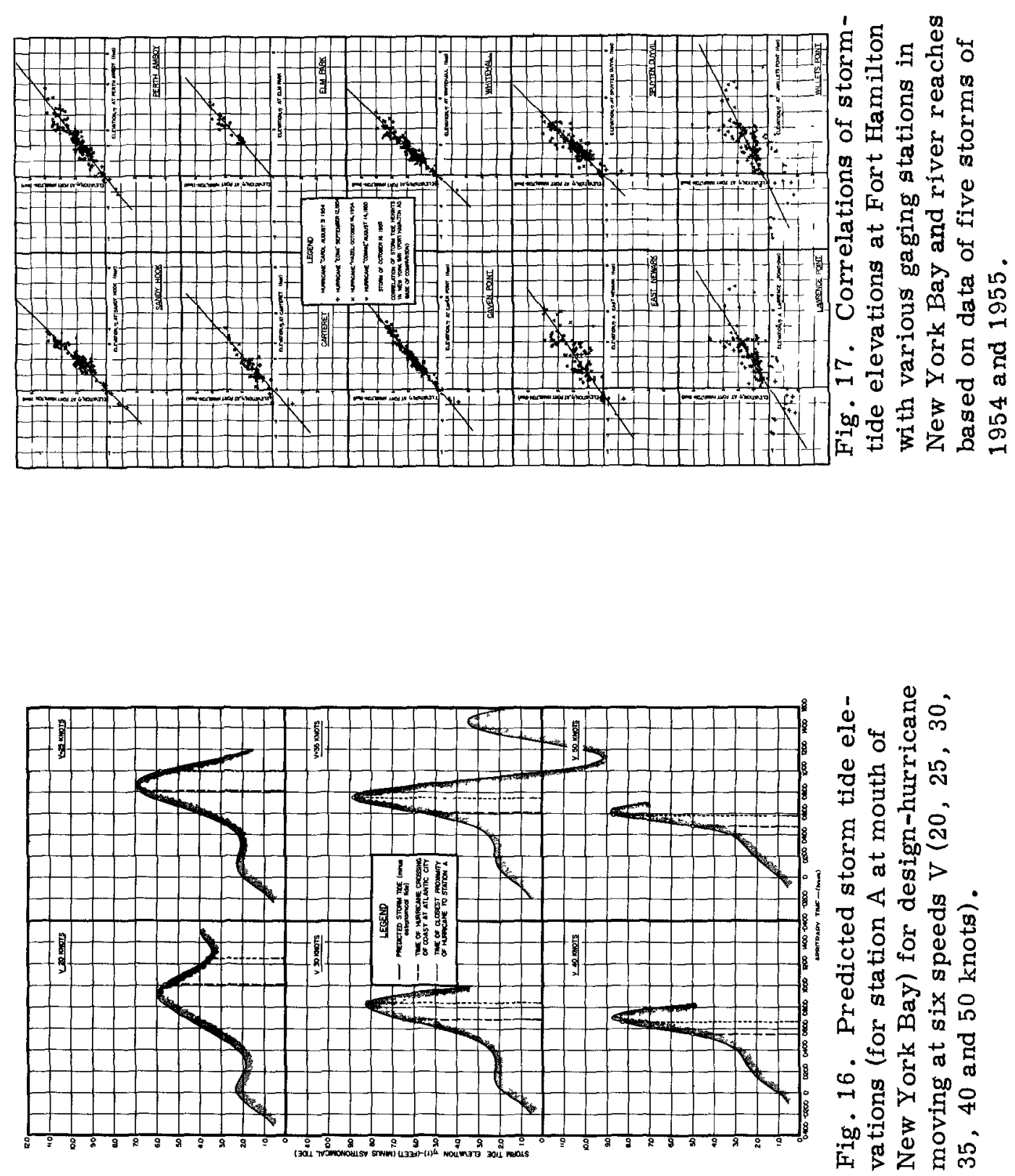


\section{COASTAL ENGINEERING}

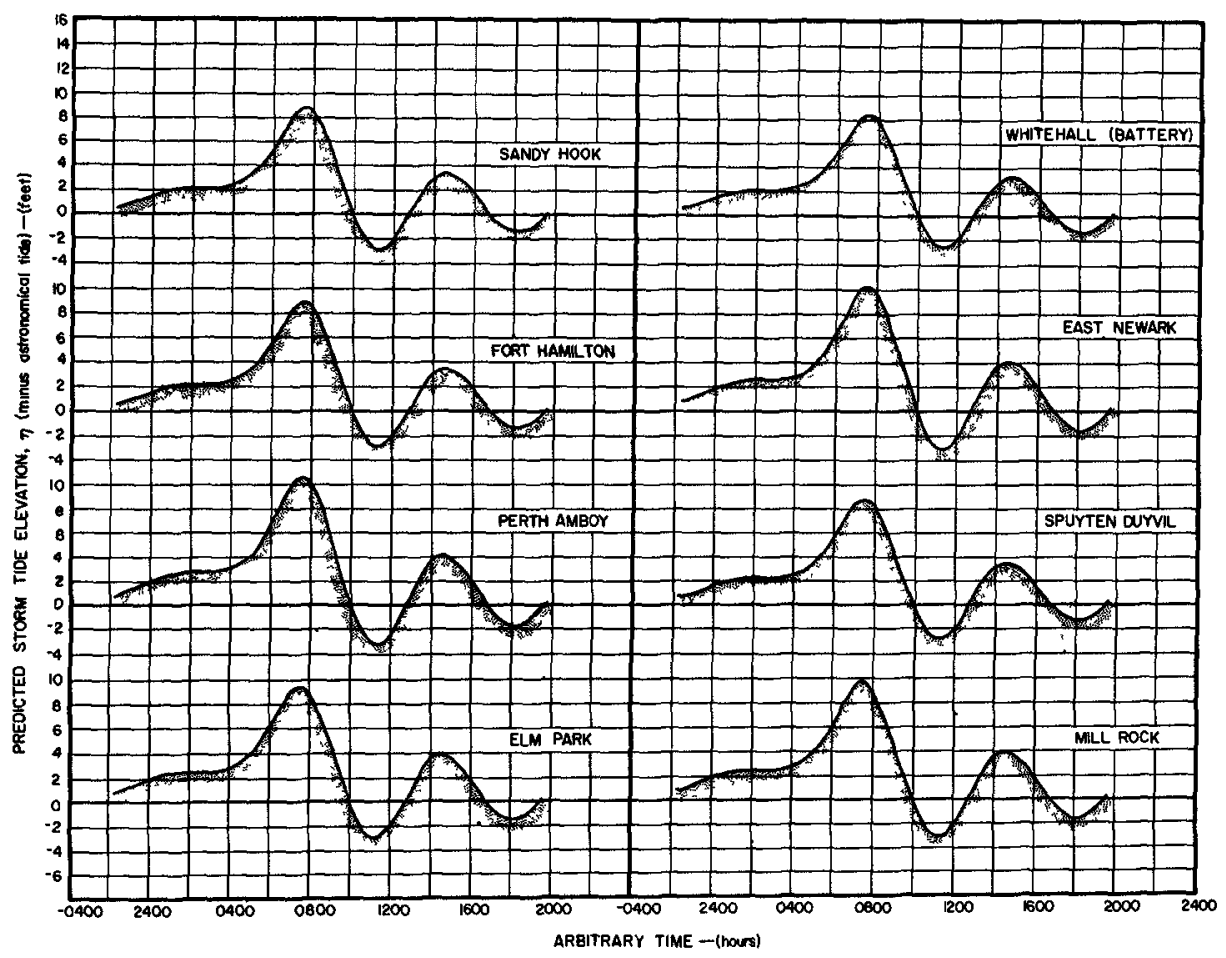

Fig. 18. Predicted storm tide elevations at eight gaging stations inside New York Bay for design-hurricane moving at speed $V<35$ knots.

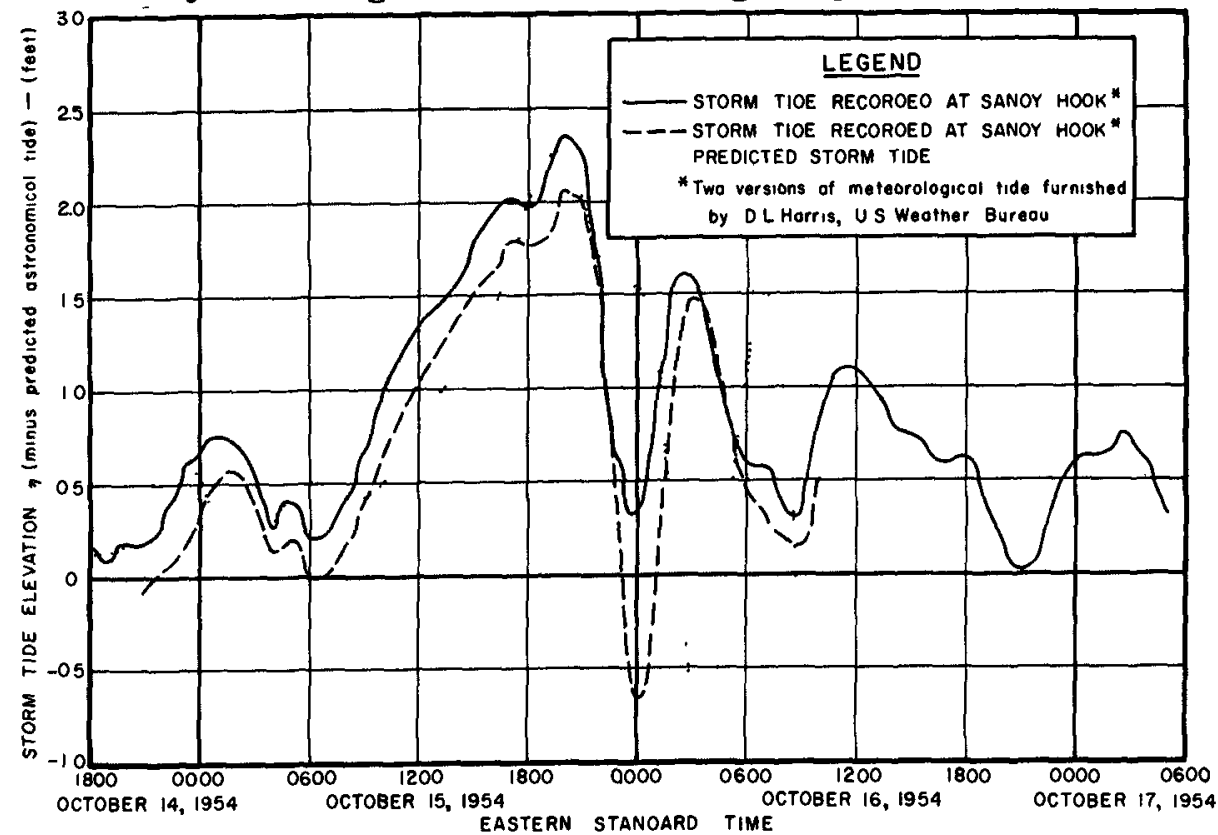

Fig. 19. Comparison of actual and predicted storm-tides at Sandy

Hook for Hurricane 'Hazel' of October 14-17, 1954. 
Forcing functions for this storm were worked out for 6 different storm speeds; $20,25,30,35,40$ and 50 knots. In applying the prediction formula, Eq. (38), with the coefficient values (44), it was necessary to start with two initial elevations $\eta_{A}(t-1 / 3)$ and $\eta_{A}(t-2 / 3)$. Since there is invariably a small superelevation of water level above normal for many hours preceding the advent of a hurricane it was appropriate to adopt 6 ins $(0.5 \mathrm{ft})$ for each of these elevations.

The results of applying the prediction formula (taking $T_{V}=0$ ) are shown in Fig. 16. The predicted storm tides all show the antecedent minor surge, characteristic of the 1938 hurricane in Fig. 8, before the main surge which occurs at or near the time of the hurricane's crossing of the coast. At the lower storm speeds ( $V=20$ and 25 knots) the peak surge occurs before arrival of the hurricane; at the higher storm speeds $(V=35,40$ and 50 knots) the peak follows after the hurricane*. The other direct influence of the storm speed is to increase the height of the peak surge from $6 \mathrm{ft}$. at $\mathrm{V}=20$ knots to a maximum of $8.9 \mathrm{ft}$. at $\mathrm{V}=35$ knots after which at the higher speeds it declines slightly. The critical speed for the design-hurricane would thus appear to be about 35 knots (or higher), with very little to choose between the magnitudes of the resulting surges at speeds greater than 35 knots.

Reverting to Figs. 8 and 9 it may be noticed that phase differences between storm-tide superelevations at the various gaging stations are not very considerable in relation to the 7 -hour period of the resurgences. This suggests that correlations between levels at different stations might obey simple linear regression. The results of graphical correlation using data for five storms of 1954 and 1955 are shown in Fig. 17 and indicate, by and large, that the relationships are linear though the confidence limits become rather broad for the upriver gaging stations, presumably owing to the influences on water level there of the ocean outlet through Long Island Sound (cf. Fig. 7). The regression lines of Fig. 17 are supported by the data of the four reference storms (not shown).

In Fig. 18 use is made of the relationships of Fig. 17 to predict the design-hurricane storm-tides at eight of the gaging stations in New York Bay. Thus the predicted tide at Sandy Hook is taken the same as $\eta_{A}(t)$ predicted for station $A$ at the bay-mouth (Fig. 4) for the design-hurricane at the speed $\mathrm{V}=35$ knots. This prediction has been extended somewhat further in time than the version shown in Fig. 16, but is otherwise the same. It must be remarked that

*This is inferred from estimates of applicable values of $\mathrm{T}_{\mathrm{V}}$. 


\section{COASTAL ENGINEERING}

the four curves on the right-hand of Fig. 18 are liable to considerable

fluctuation in height and relative phasing.

\section{PROOF-TEST OF THE PREDICTION METHOD; HURRICANE "HAZEL" OF 1954}

Until quite recently the prediction formula, Eq. (38), had not been prooftested by applying it to any fifth storm whose meteorological parameters were known and whose effects in New York Bay had been measured and could be compare with the predictions. The necessary data for doing this were not available at the time of completion of the study in 1959. D. L. Harris of the United States Weather Bureau, meanwhile, has evaluated the forcing functions [cf, Eqs. (39) and (40)] for hurricane "Hazel", of October 15-16, 1954, which crossed the U. S. east coast south of Cape Hatteras and pursued a track overland into the heart of the northeastern states. These functions have now been used in the prediction formula, Eq. (38), in conjunction with the coefficient values (44), with the end-results shov by the chain-dot curve in Fig. 19. In making this computation the lag correction $\mathrm{T}_{\mathrm{V}}$ was taken zero, in the absence of any specific knowledge of its value.

For comparison with the prediction Fig. 19 shows two versions of the stor 1 tide recorded at Sandy Hook, as supplied to the writer by D. L. Harris. It is not known which of these is actually correct, but in either case the prediction is in reasonable accord as to the magnitudes of the main surge and the first resurgence. The fact that the predicted resurgence is out of phase with the actual may possibly be ascribed to the assumption of a zero lag correction, $T_{V}$. However, the consequences of adopting different trial-values of $T_{V}$ have not yet been explored.

\section{CONCLUSIONS}

It would seem from the above that the storm-tide prediction formula, Eq. (38), has emerged from a singularly stringent test with considerable success and may be assumed to be capable of providing a reasonably reliable estimate of the effects on water level in New York Bay which any given hurricane or storm can produce. Further confirmation of this is forthcoming from the avallable rather crude correlations that have been made between maximum storm-tide height and central pressure $p_{o}$ within the hurricane[ cf Fig. 20]. These suggest that a storm-tide of from 10 to $12 \mathrm{ft}$ could be expected of the design-hurricane. The predicted maximum of $8.9 \mathrm{ft}$ at Sandy Hook and $10.5 \mathrm{ft}$ at Perth Amboy (Fig. 18) is within reasonable range of this spread, but accords better with the somewhat more refmed empirical system of Kajiura [1959], which suggests $10 \mathrm{ft}$.

It is felt that the prediction formula is based on sound physical reasoning and may therefore justly claim to be comprehensive in its capacity to deal twodimensionally and dynamically with any storm moving at any speed along any given 


\section{HURRICANE TIDE PREDICTION FOR NEW YORK BAY}

track.

The methods of surge prediction outlined in this paper could readily be applied to coastal stations anywhere provided sufficient data existed regarding specific storms of the past and their effects on the coastal station.

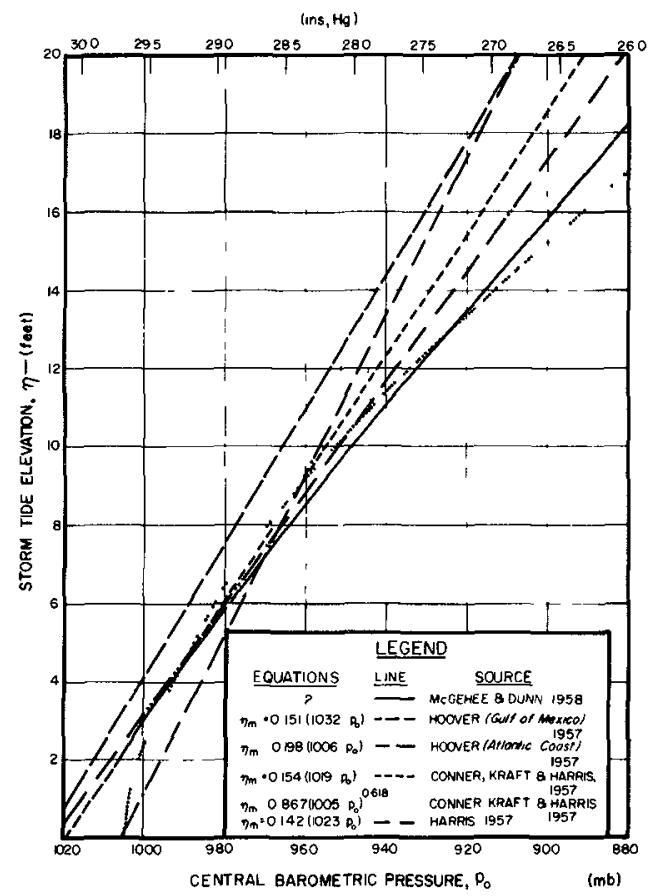

Fig. 20. Empirical correlations between maximum storm tide elevation, $\eta$, and central pressure, po, for U. S. Atlantic and Gulf Coast hurricanes.

\section{ACKNOWLEDGEMENT}

This paper is a shortened and refined version of Technical Memorandum No. 120, published recently by the Beach Erosion Board, Corps of Engineers, U.S. Army, and is made possible through kind permission of that body. The writer must record his great appreciation of the assistance and counsel rendered by R. $O$. Reid in many of the intricacies of the numerical methods, particularly in the matter of instability. To R. L. Smith and R. E. Kilmer, moreover, belongs the considerable credit for programming and conducting the involved correlations and predictions on the IBM No. 650 electronic computer. The writer is also indebted to D. L. Harris for his interest and constructive criticism and for furnishing data in respect of hurricane Hazel. Completion and presentation of this paper would not have been possible without the final s ponsorship of the Office of Naval Research, U. S. Navy, [Contracts N7 onr 48702 and N onr 2119 (02)], which is gratefully acknowledged. 


\section{COASTAL ENGINEERING}

\section{REFERENCES}

Conner, W. C., Kraft, R. H. and Harris, D. L. [1957]; Empirical methods of forecasting the maximum storm tide due to hurricanes and other tropical storms; Monthly Weather Review, v. 85, 1957, pp. 113-116.

Corkan, R. H. [1950]; The levels in the North Sea associated with the storm disturbance of 8 Jan. 1949; Trans. Roy. Soc. London, v. 242 (A), July 1950 , pp. 493-525.

Darbyshire, J. and Darbyshire, M. [1956]; Storm surges in the North Sea during the winter 1953-4; Proc. Roy. Soc., v. 235, A, 1956, pp. 260-274.

Donn, W. L. [1958]; An empirical basis for forecasting storm tides, Bulln. Am. Met. Soc., v. 39 (12), Dec. 1958, pp. 640-647.

Dunn, G. E. [1957]; Hurricanes and hurricane tides; Proc. 6th Coast. Eng. Conf. (Gainsville, Fla., 1957), Council Wave Research, Berkeley, 1958, pp. 19-29.

Fischer, G. [ 1959]; Ein numerische Verfahren zur Errechnung von Windstau und Gezetten in Randmeeren; Tellus, v. VII (i), 1959, pp. 60-76.

Hansen, W. [1957]; Theorie zur Errechnung des Wasserstandes und der Stromungen in Randmeeren nebst Andwendungen; Tellus, v. 8, 1956, pp. 287-300.

Hansen, W. [ 1957]; A method of calculation of long period waves, Communication I, Section II, XIXth International Navigation Congress, London, 1957 (Brussels, Belgium, 1957).

Harris, D. L. [1956]; Some problems involved in the study of storm surges; Report No. 4, Nat'1. Hurricane Research Project, U. S. Weather Bureau, Dec. $1956,30 \mathrm{pp}$.

Harris, D. L [1957]; The hurricane surge; Proc. 6th Coast. Eng. Conf. (Gainsville, Fla., 1957), Council Wave Research, Berkeley, 1958, pp. 96114.

Harris, D. L [1959]; An interim hurricane storm surge forecasting guide; Report No. 32, Nat ${ }^{\top} 1$. Hurricane Research Project, Weather Bureau, U. S. Dept. Commerce, Aug., 1959, 24 pp. 
Hoover, R. A. [1957]; Empirical relationships of the central pressures in hurricanes to the maximum surge and storm tide; Monthly Weather Review, v. 85,1957, pp. $167-174$.

Kajiura, K. [1959]; A theoretical and empirical study of storm induced water level anomalies; Tech. Report (Ref. 59-23F), Texas A. and M. Research Foundation, College Station, Tex., Dec., 1959, 97 pp.

Kivisild, H. R. [1954]; Wind effect on shallow bodies of water with special reference to Lake Okeechobee; Bulletin No. 43, Inst. Hydraulics, Roy. Inst. Tech., Stockholm (Goteborg, 1954), 146 pp.

Kussman, A. S. [1957]; The storm surge problem in New York City; Trans. New York Acad. Sci. , Ser. II, v. 19 (8), June 1957, pp. 751-763.

Lamb, H. [1932 Ed. ]; Hydrodynamics, (Cambridge Univ. Press, England), 1932 Ed. (1st Ed. 1879).

Miller, A. R. [1956]; The effect of steady winds on sea level at Atlantic City; Meteorological Monographs (Am. Met. Soc.), v. 2(10), June 1957, pp. 2431 .

Miller, A. R. [1957]; Report on the effect of winds on coastal water levels of New England; Report (Ref. No. 57-22), Woods Hole Oceanographic Institution, Woods Hole, Mass. , Mar. 1957 (unpublished).

Moore, P. L. et al., [1957]; The hurricane season of 1957; Monthly Weather Review, v. 85, 1957, pp. 401-408.

Munk, W., Snodgrass, F. and Carrier, G. [1956]; Edge waves on the continental shelf; Science, v. 123, 1956, pp. 127-132.

Platzman, G. W. [1958]; A numerical computation of the surge of 26 June 1954 on Lake Michigan; Tech. Report No. 1, Dept. Meteorology, Univ. of Chicago, June $1958,32 \mathrm{pp}$.

Redfield, A. C. and Miller, A. R. [1956]; Water levels accompanying Atlantic Coast hurricanes; Meteorological Monographs (Am. Met. Soc.), v. 2 (10) June 1957 , pp. 1-23.

Reid, R. O. [1955]; On the classification of hurricanes by storm tide and wave energy indices; Meteorological Monographs (Am. Met. Soc., ), v. 2(10), June 1957, pp. $58-66$. 


\section{COASTAL ENGINEERING}

Reid, R. O. [1956]; Approximate response of water level on a sloping shelf to a wind fetch which moves towards shore; Tech. Memo. No. 83, Beach Erosion Board, Corps of Engrs., U. S. Army, June 1956, 44 pp.

Reid, R. O. [ 1957 (i)]; Comments on the Conference on Long Waves and Storm Surges held at the Nat'1. Inst. of Oceanography, England, May 27 31,1957 , (unpublished).

Reid, R. O. [ 1957 (ii)]; Forced and free surges in a narrow basin of variable depth and width: A numerical approach; Tech. Report (Ref. 57-25T), Texas A. and M. Research Foundation, Aug. 1957, 60 pp. (unpublished).

Schalkwijk, W.F. [1947]; A contribution to the study of storm surges on the Dutch Coast; Roy. Netherlands Meteor. Inst., v. 125, B, Part I (7).

Tancreto, A. E. [1958]; A method for forecasting the maximum surge at Boston due to extratropical storms; Monthly Weather Review, U. S. Weather Bureau, v. $86(6)$, June 1958 , pp. $197-200$.

Weenink, M. P. H. [1956]; The 'Twin' Storm Surges during 21-24 December 1954 - A case of resonance; Deutsche Hydrogr. Zeibschr., v. 9, 1956, pp. 240-249.

Weenink, M. P. H. and Groen, P. [1958]; A semi-theoretical, semi-empirical approach to the problem of finding wind effects on water levels in a shallow, partly-enclosed sea, I and II; Proc. Korinkl. Ned. Akad. Wetensch., v. 61 (B') 1958, pp. 198-213.

Wilson, B. W. [1960]; Note on surface wind stress over water at low and high wind speeds; Jour. Geophys. Research, 1960 (publication pending).

Wilson, B. W. [1960]; The prediction of hurricane storm tides in New York Bay; Tech. Memo No. ' 120 , Beach Erosion Board, Corps of Engrs., U. S. Army, Aug. 1960.

Zetler, B. D. [1957]; Hurricane effect on sea level at Charleston, Proc. ASCE, v. 83 (HY 4), Paper No. 1330, Aug. 1957,19 pp. 